\title{
Asymptomatic Cerebral Small Vessel Disease: Insights from Population-Based Studies
}

\author{
Alvin S. Das, ${ }^{\mathrm{a}, \mathrm{b}}$ Robert W. Regenhardt, ${ }^{\mathrm{a}, \mathrm{b}}$ Meike W. Vernooij, ${ }^{\mathrm{c}, \mathrm{d}}$ Deborah Blacker, ${ }^{\mathrm{e}, \mathrm{f}}$ \\ Andreas Charidimou, ${ }^{\mathrm{a}}$ Anand Viswanathan ${ }^{\mathrm{a}}$ \\ ${ }^{a}$ Department of Neurology, Massachusetts General Hospital, Harvard Medical School, Boston, MA, USA \\ 'Department of Neurology, Brigham and Women's Hospital, Harvard Medical School, Boston, MA, USA \\ 'Department of Epidemiology, Erasmus University Medical Center, Rotterdam, the Netherlands \\ ${ }^{\mathrm{d} D e p a r t m e n t}$ of Radiology, Erasmus University Medical Center, Rotterdam, the Netherlands \\ 'Department of Psychiatry, Massachusetts General Hospital, Harvard Medical School, Boston, MA, USA \\ fDepartment of Epidemiology, Harvard T.H. Chan School of Public Health, Boston, MA, USA
}

Cerebral small vessel disease (CSVD) is a common group of neurological conditions that confer a significant burden of morbidity and mortality worldwide. In most cases, CSVD is only recognized in its advanced stages once its symptomatic sequelae develop. However, its significance in asymptomatic healthy populations remains poorly defined. In population-based studies of presumed healthy elderly individuals, CSVD neuroimaging markers including white matter hyperintensities, lacunes, cerebral microbleeds, enlarged perivascular spaces, cortical superficial siderosis, and cerebral microinfarcts are frequently detected. While the presence of these imaging markers may reflect unique mechanisms at play, there are likely shared pathways underlying CSVD. Herein, we aim to assess the etiology and significance of these individual biomarkers by focusing in asymptomatic populations at an epidemiological level. By primarily examining population-based studies, we explore the risk factors that are involved in the formation and progression of these biomarkers. Through a critical semi-systematic review, we aim to characterize "asymptomatic" CSVD, review screening modalities, and draw associations from observational studies in clinical populations. Lastly, we highlight areas of research (including therapeutic approaches) in which further investigation is needed to better understand asymptomatic CSVD.
Correspondence: Anand Viswanathan J. Philip Kistler Stroke Research Center, Department of Neurology, Massachusetts General Hospital, Harvard Medical

School, 175 Cambridge Street, Suite 300, Boston, MA 02114, USA

Tel: +1-617-643-3876

Fax: +1-617-726-5346

E-mail: aviswanathan1@partners.org

Received: December 25, 2018

Revised: January 30, 2019

Accepted: February 28, 2019

Keywords Cerebral small vessel diseases; Epidemiology; Stroke, lacunar; Leukoaraiosis

\section{Introduction}

Several of the recent developments ${ }^{1-5}$ in stroke care have focused on the treatment of large vessel occlusions and pathologies. However, there have been few advancements in the management of cerebral small vessel disease (CSVD) largely because small vessels are difficult to observe radiographically and their underlying pathogenic mechanisms are incompletely understood. ${ }^{6,7}$ This is problematic given that CSVD contributes to a number of clinically relevant sequelae including hemorrhagic stroke, vascular cognitive impairment (VCI), gait disturbances including parkinsonism, bladder dysfunction, and epilepsy. ${ }^{7-13}$ Furthermore, a large proportion of ischemic stroke and dementia are attributed to CSVD (20\% and 45\%, respectively). ${ }^{14}$ One of the greatest challenges is that there are limited means to assess CSVD prior to the development of its clinical sequelae. Moreover, even after identification of CSVD in healthy populations, management of this disease is not well established. In 
this review, we aim to summarize basic definitions of CSVD and CSVD biomarkers, highlight our current understanding of CSVD as it relates to "healthy" populations, and where relevant, incorporate evidence from observational studies in different clinical populations. We will focus on asymptomatic CSVD, defined as neuroimaging evidence of CSVD prior to the development of any overt clinical symptoms. Although we will review the major population-based studies in the field, we will crosslink our findings with those of clinical cohorts to unravel clinical relevance and put data into perspective. The emphasis of this paper will be sporadic non-amyloid CSVD (often termed "hypertensive arteriopathy"), as there are several recent reviews that discuss monogenetic CSVD and cerebral amyloid angiopathy (CAA)-related CSVD. ${ }^{15-18}$

\section{Methods}

\section{Search strategy and selection criteria}

Articles from January 1951 to July 2018 were identified through searching the PubMed (National Center for Biotechnology Information, National Library of Medicine) database. The following title/abstract search terms were employed: "cerebral small vessel disease AND population," "silent lacunar infarcts AND population," "white matter hyperintensities AND population," "cerebral microbleeds AND population," "perivascular spaces AND population," "cortical superficial siderosis AND population," and "cerebral microinfarcts AND population." Exclusion terms were not used in the search criteria. Searches were limited to full-text articles available in English. Additional references were selected by reviewing the reference lists of relevant publications. As this review was restricted to asymptomatic disease, most articles discussing symptomatic stroke or intracerebral hemorrhage (ICH) were excluded. Furthermore, we excluded literature pertaining to CAA given that our focus was on sporadic, non-amyloid CSVD.

\section{Data analysis}

By using the above search methodology, 642 articles were generated. Articles were independently screened by two authors (A.S.D. and R.W.R.) for appropriateness and relevance to the topic. Two hundred and eight articles were ultimately selected for incorporation in this review. Using this analysis, we generated a semi-systematic review.

\section{CSVD definitions}

CSVD is a broad term that incorporates both neuroimaging and neuropathological findings that pertain to smaller vessels $(5 \mu \mathrm{m}$ to $2 \mathrm{~mm}$ ) in the gray and white matter including arterioles, cap- illaries, and venules. . $^{6,14,19}$ While both concepts have been raised in the literature, it should be noted that neuroimaging markers reflect CSVD, but do not define the disease in its entirety. CSVD is often diagnosed by neuroimaging features seen occasionally on computed tomography (CT), but more sensitively detected by magnetic resonance imaging (MRI). These MRI markers include white matter hyperintensities (WMHs) of presumed vascular origin, recent small subcortical infarcts and lacunes, cerebral microbleeds (CMBs), perivascular spaces (PVSs), cortical superficial siderosis (CSS), brain atrophy, and cerebral microinfarcts (CMIs) (Figure 1). ${ }^{7.14}$ In 2013, these imaging markers (with the exception of CMI) were defined by the STandards for Reportlng Vascular changes on nEuroimaging (STRIVE) consortium, which unified definitions of CSVD biomarkers based on key neuroimaging characteristics. ${ }^{20}$ In most cases, not all of these neuroimaging markers will be present together in a single brain scan. Whether the presence or anatomical location of certain imaging markers reflects distinct small vessel pathways is not fully understood.

While the true burden of CSVD is not known, estimates suggest that at least one-third of healthy-populations have lacunes (the majority of which are due to CSVD), although the actual prevalence of CSVD is likely much higher. ${ }^{21,22}$ While these, often called "silent strokes," are visible on CT or MRI, they por-

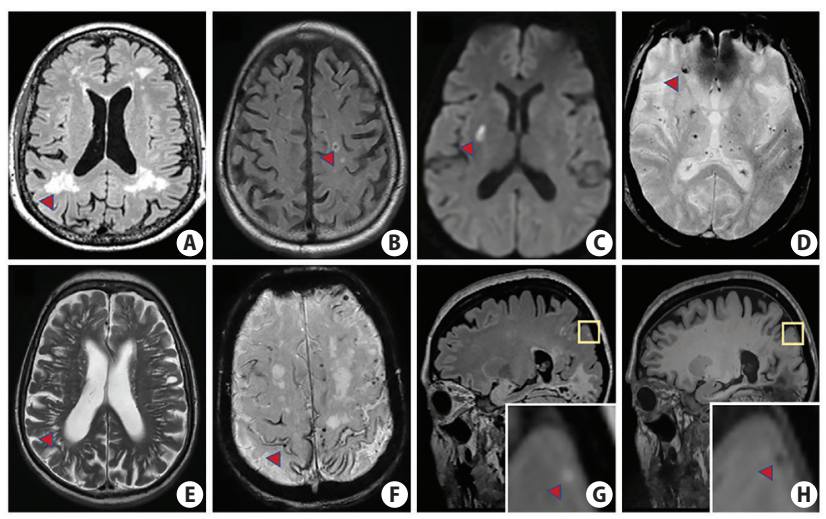

Figure 1. Imaging features of cerebral small vessel disease biomarkers on magnetic resonance imaging. (A) T2 fluid attenuated inversion recovery (FLAIR) sequence depicting white matter hyperintensities (red arrowhead) which are seen as hyperintense regions in the white matter. (B) Lacune (red arrowhead) on FLAIR sequence characterized by a central hypointensity with a surrounding rim of hyperintensity. (C) Recent subcortical infarct (red arrowhead) on diffusion-weighted imaging sequence between 3 to $15 \mathrm{~mm}$ in diameter. (D) Susceptibility-weighted imaging (SWI) sequence showing cerebral microbleeds (red arrowhead) which are round/oval shaped signal voids $\leq 10 \mathrm{~mm}$ and have associated blooming artifact. (E) Perivascular spaces (red arrowhead) on T2 which are linear cavitations that do not have a surrounding rim of hyperintensity and are $<3 \mathrm{~mm}$ in diameter. (F) Cortical superficial siderosis (red arrowhead) visualized on SWI and characterized by a curvilinear hypointensity that follows the gyral surface. (G) Cerebral microinfarct ( $<5 \mathrm{~mm}$ in diameter) is hyperintense on T2 FLAIR (see inset, red arrowhead) and $(\mathrm{H})$ hypointense on T1 (see inset, red arrowhead). Images $(\mathrm{G})$ and $(\mathrm{H})$ were graciously provided by Susanne Van Veluw. 
tend no clinical syndrome because of their small size and noneloquent location (sparing motor cortices, cranial nerves, or language centers). However, in patients without CSVD visible on 1.5T MRI, infarcts may still be present, but visible only on ultra-high resolution (7T) MRI images or by pathologic examination. The burden of these $\mathrm{CMI}$ can be formidable, with estimates suggesting hundreds to thousands of infarcts in a single brain. ${ }^{23-25}$ This fact underscores the difficulty of diagnosing and ascertaining the extent of CSVD, such that the mere presence of one biomarker such as WMH can reflect a much larger process involving several pathological disruptions to the cerebral microvasculature. ${ }^{26}$

CSVD is a dynamic process in which lesions including $\mathrm{WMH}_{1}$ $\mathrm{CMB}$, and lacunes can progress or regress (even after accounting for differences in MRI technique). ${ }^{27,28}$ The implications of this on CSVD is not well understood but may be a balance between small vessel arteriopathy and neural repair processes. Hypertension and other vascular risk factors are believed to be the primary culprits of this entity as we will see from several epidemiological studies. Herein, we aim to review the epidemiological studies that pertain to each of the major neuroimaging markers. We limit discussion of brain atrophy, given that it can reflect a host of underlying mechanisms beyond CSVD.

\section{White matter hyperintensities of presumed vascular origin}

WMH of presumed vascular origin, often termed leukoaraiosis in early reports, ${ }^{29-31}$ are of variable size, but appear hyperintense on T2-weighted (T2) and fluid attenuated inversion recovery
(FLAIR) MRI sequences and hypointense/isointense on T1weighted sequences. ${ }^{20}$ They are more difficult to detect on CT, but may be seen as hypodensities (or hypoattenuated areas). Typically, they spare the subcortical U-fibers, and presumably are due to chronic hypoperfusion with increased blood-brain barrier permeability, ${ }_{1}^{31-33}$ although pathological reports have been infrequent and discordant. ${ }^{34}$ Mechanistic insight provided by advanced neuroimaging methods suggests that there are likely early alterations in interstitial fluid mobility that eventually lead to demyelination and axonal damage. ${ }^{34}$ Because WMH are highly prevalent in "healthy" populations (Table 1), ${ }_{1}^{35-44}$ it remains unclear whether WMH are always pathologic. However, punctate WMH are probably due to a variety of causes and have relatively low risk for further progression. On the other hand, confluent WMH are likely to progress in a more aggressive fashion. ${ }^{45}$ While not fully clear, subcortical WMH and periventricular WMH may represent the same spectrum of disease leading to devastating clinical outcomes. ${ }^{34,46}$ Because of limitations in neuroimaging techniques and MRI processing methods, differentiating WMH from other lesions or artifacts (such as corticospinal tracts or blood flow) can be difficult. ${ }^{34}$

Several population-based studies have explored the risk factors associated with development of CSVD. The major studies include the Cardiovascular Health Study (CHS), Austrian Stroke Prevention Study (ASPS), Rotterdam Study (RS), and Atherosclerosis Risk in Communities Study (ARIC). While these studies have yielded several conflicting results, there are some patterns that have emerged. In the $\mathrm{CHS}_{1}^{35,36,47-53}$ a longitudinal study of elderly ( $\geq 65$ years) community-dwelling adults, approximately three-fourths of the study population exhibited periventricular

Table 1. Major population-based studies of WMH in healthy subjects

\begin{tabular}{|c|c|c|c|c|c|c|c|}
\hline Population-based study & Year & Study size & $\begin{array}{l}\text { Mean } \\
\text { age (yr) }\end{array}$ & $\begin{array}{c}\text { WMH } \\
\text { burden (\%) }\end{array}$ & WMH risk factors & $\begin{array}{l}\text { WMH progression } \\
(\%) \text { (duration, yr) }\end{array}$ & WMH progression risk factors \\
\hline $\begin{array}{l}\text { Cardiovascular Health } \\
\text { Study }{ }^{35,36}\end{array}$ & 1989 & 3,301 & 74 & 96 & $\begin{array}{l}\text { Age, silent infarct, SBP, } \\
\text { lower } \mathrm{FEV}_{1} \text {, low income }\end{array}$ & $28(5)$ & $\begin{array}{l}\text { Age, DBP, decreased LDL (low grade); } \\
\text { diuretics use, statin use (high grade); } \\
\text { cigarette smoking, baseline infarct } \\
\text { (both) }\end{array}$ \\
\hline $\begin{array}{l}\text { Austrian Stroke Prevention } \\
\text { Study }{ }^{40,41}\end{array}$ & 2005 & 273 & 60 & 65 & NR & $17.9(3)$ & Baseline WMHV, DBP \\
\hline Rotterdam Scan Study ${ }^{37,38}$ & 1990 & 1,077 & 72 & 95 & Age, female gender & $39(3.4)$ & $\begin{array}{l}\text { Baseline WMHV, female sex, age, BP, } \\
\text { smoking }\end{array}$ \\
\hline $\begin{array}{l}\text { Atherosclerosis Risk in } \\
\text { Communities Study }{ }^{39,42}\end{array}$ & 1987 & 1,920 & 62 & 86 & $\begin{array}{l}\text { Age, smoking, alcohol use, } \\
\text { education, SBP, DBP, Af- } \\
\text { rican American race }\end{array}$ & $23(9)$ & SBP, smoking \\
\hline $\begin{array}{l}\text { Framingham Offspring Co- } \\
\text { hort Study }{ }^{43,44}\end{array}$ & 1948 & 1,814 & 53 & NR & Smoking, hypertension & NR (10) & Smoking, BP \\
\hline
\end{tabular}

For each population-based study, the percentage of patients with WMHs is shown. The percentage of individuals with WMH progression is shown as well as the duration of study in parenthesis. Risk factors for WMH formation as well as progression are listed.

WMH, white matter hyperintensity; SBP, systolic blood pressure; FEV ${ }_{1}$, forced expiratory volume in 1 second; DBP, diastolic blood pressure; LDL, low-density lipoprotein; NR, not reported; WMHV, white matter hyperintensity volume; BP, blood pressure. 
rather than subcortical WMH and about one-fifth of population had equal distributions in both regions. Higher WMH burden was associated with older age, asymptomatic stroke on MRI, higher systolic blood pressure (BP), smoking, and female gender, with age showing the strongest correlation. ${ }^{35}$ By contrast, the majority of WMH in the RS, a population based-cohort study that recruited nondemented individuals aged 60 to 90 years, ${ }^{37,54-57}$ were found in subcortical areas and to greater extent in frontal and parietal regions. ${ }^{37,38}$ As shown in a substudy of the RS, arterial stiffness (as measured by the aortic pulse wave velocity) was associated with larger WMH volumes independent of cardiovascular risk factors. ${ }^{58}$ Similar to $\mathrm{CHS}$, WMH were also associated with increasing age. Regardless of age or anatomic location, women had a higher burden of white matter lesions (both in periventricular and subcortical areas) consistent with findings from the PROspective Study of Pravastatin in the Elderly at Risk (PROSPER) study ${ }^{59,60}$ as well as CHS. This may be due to decreased estrogen after menopause allowing the brain to be more prone to hypoxia. ${ }^{37}$ Interestingly, in a longitudinal substudy of PROSPER, ${ }_{1}^{59}$ deep WMH progression among women was twice that of men, whereas the increase in periventricular WMH was similar. ${ }^{60}$ In the ARIC study, a prospective study that recruited middle-aged men and women, ${ }^{61}$ hypertension was associated with WMH. ${ }^{39,62}$ For unclear reasons, blacks had a lower prevalence of WMH, but a higher prevalence of severe WMH. ${ }^{63}$ In a follow-up study, blacks, who had a higher incidence of baseline hypertension, experienced more WMH progression than Caucasians. ${ }^{64}$ Unlike many of the other population-based studies (in which blacks were less represented), this finding suggests that hypertension may influence CSVD progression. However, it is uncertain whether black race is independently associated with WMH burden or whether hypertension contributes indirectly. In addition to blacks, Asians have a high burden of CSVD, ${ }^{65,66}$ although the location of their WMH is similar to that of Europeans, but more strongly associated with age. ${ }^{67}$ Similar to blacks, hypertension is also strongly associated with WMH burden in Asian populations. ${ }^{68}$

In early longitudinal studies, baseline CSVD (lacunes and $\mathrm{WMH}$ ) seems to have the strongest association with $\mathrm{WMH}$ progression, although there has been conflicting information regarding whether WMH progression occurs in periventricular or subcortical (deep) areas..$^{69-73}$ In follow-up studies examining the progression of WMH in the CHS, the risk of clinical stroke was increased among patients with high baseline WMH burdens and asymptomatic strokes. ${ }^{36,52,74}$ Interestingly, with the exception of cigarette smoking and presence of an infarct on baseline MRI, the relationship between risk factors and WMH progression was dependent on low versus high WMH burden at initial scan (Table 1) ${ }^{36}$ Baseline WMH burden was also found to be important in the ASPS, a single-center population-based study that enrolled around 2,000 individuals in Graz, Austria, ages 50 to $75 .{ }^{40,75}$ In a 3-year period, subcortical WMH progression occurred in deep and subcortical areas, and was associated with diastolic BP as well as baseline WMH burden. ${ }^{40}$ However, in a 6-year follow-up study, only baseline WMH grade was ultimately associated with $\mathrm{WMH}$ progression. ${ }^{41,76}$ Similar to the ASPS, the RS showed that WMH progression occurs in subcortical areas compared to periventricular areas, ${ }^{38}$ a finding which was also replicated in the Leukoaraiosis And DISability study (LADIS). ${ }^{72}$ Interestingly, one Japanese study of neurologically healthy adults demonstrated that subcortical WMH were more associated with increased future risk of stroke than periventricular $\mathrm{WMH}_{\text {, although periventricular }}$ WMH were associated with an increased risk of death. ${ }^{46}$ In the RS, WMH progression was associated with a broad range of previously-identified risk factors ${ }^{38,77}$ and in young patients and in patients without severe WMH at baseline, hypertension was strongly associated with lesion progression. Interestingly, a small percentage of subjects demonstrated WMH regression in subcortical areas (and to a much lesser extent periventricular areas), highlighting the dynamic nature of CSVD. ${ }^{27}$

In the Framingham Offspring study, WMH were associated with an increased risk of symptomatic stroke, dementia, amnestic cognitive impairment, and death. ${ }^{78-82}$ Similar studies have shown that WMH can modulate the progression from normal to mild cognitive impairment, ${ }^{83}$ with periventricular WMH playing a more critical role than deep/subcortical $W_{M M H}{ }^{84,85}$ In the RS, apolipoprotein (APOE) $\varepsilon 4$ carriers, which have increased rates of Alzheimer's disease ${ }_{1}^{86}$ had higher WMH burdens, especially if carriers had comorbid hypertension. This has been corroborated by other studies relating APOE to WMH burden. ${ }^{87-89}$ In the RS, $4.2 \%$ of subjects developed dementia, which was associated with a higher burden of periventricular WMH compared to subcortical WMH. ${ }^{90}$

\section{Recent small subcortical infarcts and lacunes}

Because of advancements in neuroimaging that have led to improved detection of asymptomatic infarcts, the STRIVE consortium separated lacunar stroke into recent small subcortical infarct and lacune of presumed vascular origin. ${ }^{20}$ Lacunes likely represent the chronic end-product of small subcortical infarcts. Recent small subcortical infarcts are sometimes accompanied by clinical lacunar syndromes, as initially described by Fish$\mathrm{er}_{1}^{91,92}$ or they can be found incidentally by lesions with re- 
stricted diffusion on diffusion-weighted imaging (DWI) without an accompanying clinical stroke syndrome. ${ }^{93,94}$ Small subcortical infarcts are dynamic, and over-time, can disappear, cavitate (forming lacunes), or form WMH. ${ }^{27,95,96}$ On imaging, small subcortical infarcts follow the territory of a perforating arteriole, are $<20 \mathrm{~mm}$ in maximal diameter, and exclude striatocapsular infarcts and anterior choroidal infarcts (which have a different underlying etiology). They are relatively easy to detect on MRI because they appear hyperintense on DWI and hypointense on apparent diffusion coefficient images. Pathologically, they are presumably due to occlusion of small perforating arterioles through a variety of mechanisms including microatheromatous disease or cardioembolism.

Lacunes of presumed vascular origin are appropriately named given the fluid-filled cavity that is often found after a lacunar stroke. By consensus definitions, lacunes are a round or ovoid, subcortical, fluid-filled cavity between 3 and $15 \mathrm{~mm}$ in diameter. They follow the signal intensity of cerebrospinal fluid on all sequences and on FLAIR images, and they have a central hypointensity with a surrounding rim of hyperintensity (in contrast to PVS). ${ }^{20}$ Incidental small subcortical infarcts are not commonly observed at high-frequencies in studies of asymptomatic populations, and so therefore our analysis will be limited to lacunes. Given that previous analysis of lacunes have been reviewed systematically, ${ }^{10,97}$ we will highlight only the major population-based studies.

In healthy populations, the frequency of lacunes ranges from $8 \%$ to $31 \%$ lowing to differences in the ages of the study populations and variability in spatial resolution of imaging studies). ${ }^{21,41,51,52,56,68,98}$ Although the associated risk factors have varied between studies, hypertension, age, and (to a lesser degree) smoking, seem to be the most replicated..$^{21,56,68,98,99}$ Conflicting associations between gender and infarct presence have been observed: in the CHS and Shunyi Study, male gender was found to be associated, ${ }_{1}^{21,68}$ and in the RS, female gender was found to be associated. ${ }^{56}$ Other less robust risk factors that have been shown to be associated with silent lacunes include serum creatinine, ${ }^{21}$ diabetes, ${ }_{1}^{21,68,99}$ cholesterol, ${ }^{99}$ homocysteine levels, ${ }_{1}^{99}$ and black race. ${ }^{98}$ Interestingly, carotid atherosclerosis was found to be associated with silent lacunes, suggesting that small subcortical infarcts can occur through artery-artery embolism or flow limiting effects. ${ }^{21,98,99}$

In these studies, lacunes were typically found in the lentiform nucleus and thalamus ${ }^{21}$ whereas a large portion of symptomatic infarcts were found in the cerebral cortex, thereby invoking other etiologies such as internal carotid artery atherosclerosis or atrial fibrillation..$^{22}$ Although many of these individuals did not experience any clinical symptoms of stroke, they were more likely to perform poorly on neuropsychological testing, highlighting the "covert" nature of CSVD. ${ }^{53}$ In longitudinal studies, the progression of lacunes occurs in $3.5 \% \%^{53}$ to $4.1 \% \%^{99}$ of subjects annually. Baseline cerebrovascular disease (WMH and lacunes) seems to be the most prominent risk factor for development of additional lacunar infarcts, which are predominantly located in subcortical regions ${ }^{53}$ or in the deep basal ganglia. ${ }^{56}$ The association between baseline WMH and infarct development suggests that there may be a common pathway underlying these two markers. Similarly, symptomatic strokes are likely to represent a lesion in the same spectrum as asymptomatic strokes. Individuals with these silent brain infarcts are twice as likely to develop symptomatic stroke, which share many of the same risk factors as silent infarcts..$^{52}$ Of the individuals that experienced a symptomatic stroke during followup studies, the majority were more likely to have a silent lacunar stroke or a higher WMH burden on their initial MRI. ${ }^{100}$

\section{Cerebral microbleeds}

CMBs are areas $(\leq 10 \mathrm{~mm})$ of round/oval shaped signal voids with blooming effect on MRI, best seen on $\mathrm{T}^{*}$-weighted gradient-recalled echo (GRE) or susceptibility-weighted imaging. ${ }^{101}$ They are located in the cortico-subcortical junction and deep gray or white matter throughout the brain (including brainstem and cerebellum). ${ }^{20,102}$ Histopathologically, in microangiopathies that affect small penetrating vessels (such as non-CAA CSVD/"hypertensive vasculopathy" or CAA), there is often extravasation of blood products into perivascular tissues leading to activation of macrophages; these foci of hemosiderin-laden macrophages are representative of microbleeds. ${ }^{103}$ Clinically, they are associated with $\mathrm{ICH}$ and stroke (especially in CAA). ${ }^{104}$ However, the clinical significance of CMB in healthy populations is poorly understood.

$\mathrm{CMB}$ are a common finding in "healthy" populations. The prevalence of $\mathrm{CMB}$ ranges from $3.1 \%{ }^{105}$ to $15.3 \%{ }^{106}$ owing to differences in the sensitivity of MRI sequences used (Table 2). In subjects with $\mathrm{CMB}$, the majority have $<3$ lesions located in cortico-subcortical areas. ${ }^{107-112}$ However, in non-European populations, CMB are found more predominantly in deep areas, which may be related to increased rates of hypertension although the prevalence of $\mathrm{CMB}$ is relatively the same. ${ }^{68,111,113,114}$ While several risk factors are associated with $\mathrm{CMB}$ presence, the two most consistently associated are age and hypertension. ${ }^{68,105-107,110,111,115}$ For example, in the Framingham Study Original Cohort and Offspring Cohort, ${ }^{108,109}$ the prevalence of CMB was $12.6 \%$ in patients 75 years of age or older compared to $2.2 \%$ in patients younger than 75 . With improved detection sensitivity using 3D- 
Table 2. Prevalence and risk factors of CMBs in healthy populations

\begin{tabular}{|c|c|c|c|c|c|c|}
\hline Population-based study & Year & Study size & Mean age (yr) & MRI field strength (T) & Prevalence (\%) & Risk factors \\
\hline $\begin{array}{l}\text { Austrian Stroke Prevention } \\
\text { Study }{ }^{107}\end{array}$ & 1999 & 280 & 60 & 1.5 & 6.4 & Age, HTN, SSI, WMH \\
\hline Tsushima et al. ${ }^{105}$ & 2002 & 450 & 53 & 1.0 & 3.1 & HTN and smoking \\
\hline Framingham Study ${ }^{115}$ & 2004 & 472 & 64 & 1.0 & 4.7 & Age, male gender \\
\hline AGES-Reykjavik ${ }^{110}$ & 2008 & 1,962 & 76 & 1.5 & 11.1 & Age, male gender, APOE $\varepsilon 4$ status \\
\hline Rotterdam Scan Study ${ }^{106}$ & 2010 & 3,979 & 60 & 1.5 & 15.3 & SBP, HTN, smoking, SSI, WMH \\
\hline RUN-DMC ${ }^{112}$ & 2011 & 485 & 66 & 1.5 & 10.7 & NR \\
\hline Atahualpa Project ${ }^{111}$ & 2015 & 258 & 70 & 1.5 & 11.0 & WMH, SSI, brain atrophy \\
\hline Mitaki et al. ${ }^{113}$ & 2017 & 4,024 & 62 & 1.5 & 4.1 & $\begin{array}{l}\text { WMH (lobar CMB), low TC and HDL-C (deep } \\
\text { CMB) }\end{array}$ \\
\hline Shunyi Study ${ }^{68}$ & 2018 & 1,211 & 56 & 3.0 & 10.6 & $\begin{array}{l}\text { Age, hypertension (deep CMB), male gender, } \\
\text { low LDL-C (deep CMB) }\end{array}$ \\
\hline
\end{tabular}

Note that all studies used gradient-echo $\mathrm{T} 2^{*}$ weighted sequences.

$\mathrm{CMB}$, cerebral microbleed; MRI, magnetic resonance imaging; T, Tesla; HTN, hypertension; SSI, small subcortical infarct; WMH, white matter hyperintensities; APOE $\varepsilon 4$, apolipoprotein $\varepsilon 4$; SBP, systolic blood pressure; NR, not reported; TC, total cholesterol; HDL-C, high-density lipoprotein-C; LDL-C, low-density lipoprotein-C.

GRE in the RS, CMB prevalence was 18\% in individuals aged 60 to 69 years and $38 \%$ in patients older than $80 .{ }^{116}$ In addition, three studies ${ }^{68,110,115}$ have found higher rates of CMB in males, although other studies have not reported any gender differences in CMB prevalence. ${ }^{107}$ As seen in other CSVD biomarkers, smoking was also identified as a risk factor in two studies ${ }^{105,106}$ while diabetes and hypercholesterolemia may be less important (Table 2). ${ }^{68,113}$ Given the overlap of risk factors in $\mathrm{CMB}, \mathrm{WMH}$, and lacunes, there are likely shared underlying mechanisms that give rise to these biomarkers. Indeed, several studies have demonstrated an increased prevalence of CMB if concomitant WMH and lacunes were present. ${ }^{106,107,111,113}$

As with other biomarkers, the location of CMB may be reflective of distinct underlying etiologies. In the ASPS, all individuals with deep CMB had hypertension, whereas only $50 \%$ of individuals with cortico-subcortical CMB had hypertension. ${ }^{107}$ In the Framingham Study, ${ }^{108,109}$ almost three-fourths of the study population had CMB in the cortex, whereas $23 \%$ were located in deep regions. Unlike the aforementioned studies, hypertension was not associated with $\mathrm{CMB}$, perhaps explained by the fact that this study included fewer subjects with deep CMB (of which hypertension is more related). In the Age Gene/Environment Susceptibility (AGES)-Reykjavik study, ${ }^{117}$ larger microbleeds were associated with hypertension, and unlike the ASPS, CMB presence was associated with ApoE $\varepsilon 4$ homozygosity. ${ }^{110}$ Similar to the Framingham Study, $70 \%$ of subjects had CMB located in cortex, whereas $11 \%$ had deep CMBs, and 19\% had infratentorial CMB. Based on these findings, CAA seemed prevalent in their population, and given the association with $A p o E$, CAA was likely the etiologic culprit. From the $\mathrm{RS}_{1}{ }^{116} \mathrm{ApoE} \varepsilon 4$ carriers had more lobar CMB compared to noncarriers, whereas patients with cardiovascular risk factors (hypertension, smoking), silent lacunar infarcts, and WMH had more deep or infratentorial CMB. These findings correlate with observed findings in $\mathrm{ICH}_{1}{ }^{118}$ and arterial stiffness findings in stroke patients. ${ }^{119}$ Interestingly, in a follow-up analysis of the $\mathrm{RS}_{1}^{120}$ it was shown that $C M B$ were more prevalent (odds ratio $[O R], 1.71$ ) in patients taking antithrombotic medications (platelet aggregation inhibitors), but not in patients on anticoagulant medications. However, it is worth noting that CMB prevalence may be confounded by some indications for antiplatelet treatment, such as stroke. ${ }^{121}$ Patients with strictly lobar CMB were found in a higher proportion among aspirin users $(O R, 2.70)$ compared to carbasalate calcium users (a combination formula of calcium acetylsalicylate and urea; $O R, 1.16)$, suggesting that aspirin worsens $\mathrm{CMB}$ burden in patients with CAA.

Even in clinically healthy persons, the presence of CMB correlates with numerous future risks. In the $R S$, the presence of $\mathrm{CMB}$ almost doubled the risk of ischemic stroke in a 5-year period, with greater $\mathrm{CMB}$ count associated with higher stroke risk. ${ }^{118}$ In the PROSPER trial, subjects with greater than $1 \mathrm{CMB}$ had a six-fold increase in stroke-related death than those without CMB. ${ }^{122}$ Nonlobar CMB were associated with an increased risk of cardiovascular death whereas lobar CMB was associated with an elevated risk of stroke-related death. ${ }^{123}$ CMB have also been associated with gait disturbances in nondemented persons. ${ }^{112,124}$ Furthermore, subjects with $\geq 2 \mathrm{CMB}$ performed poorly on tests of processing speed and executive function, especially those with multiple, deep or infratentorial CMB. ${ }^{125}$ The presence of these deep CMB doubled the risk of 
vascular dementia $(\mathrm{VaD})$. Subjects with both $\mathrm{CMB}$ and concomitant retinopathy were most likely to exhibit slow processing speeds, poor executive function, and VaD. ${ }^{125}$ Other studies have shown that subjects with numerous $(\geq 5)$ lobar CMB had more robust associations with cognitive dysfunction than did subjects with deep CMB. ${ }^{106,126}$ However, in the Framingham Heart Study, strictly lobar CMB were not associated with an increased risk of dementia. ${ }^{127}$ Collectively, these studies suggest that deep CMB may contribute to cognitive decline through mechanisms distinct from lobar CMB-associated cognitive dysfunction. ${ }^{126}$ The former like reflects sporadic, non-amyloid CSVD whereas the latter reflects CAA.

\section{Enlarged perivascular spaces}

PVSs, sometimes referred to as Virchow-Robins spaces, are linear (but can be ovoid or round) projections that follow the path of blood vessels. Their significance is unclear, although they may be involved in the drainage of interstitial fluid and may be implicated in neurological diseases. ${ }^{128}$ Normally, they are not well visualized by conventional MRI; however, as these spaces dilate (with age or other pathological conditions), they may be seen as fluid-filled spaces in both the gray and white matter. ${ }^{20}$ They are usually $<3 \mathrm{~mm}$ in maximal diameter, a cutoff that has often been used to distinguish these from lacunes, which also contain a hyperintense $\mathrm{T} 2$ rim surrounding the cavitation.

Similar to other biomarkers, the spatial distribution of PVS may reflect distinct mechanisms such that deep PVS are likely caused by hypertensive-CSVD whereas white matter PVS may be more driven by CAA. Such anatomical distinctions have also been observed in PVS found after ICH. ${ }^{129}$ In patients presenting to a memory clinic, white matter PVS were associated with lobar CMB whereas basal ganglia PVS were associated with older age, hypertension, and higher WMH volumes. ${ }^{130}$ Similarly, in a healthy Japanese cohort, basal ganglia PVS were associated with in-

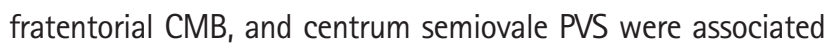
with strictly lobar CMB. ${ }^{131}$ Furthermore, basal ganglia PVS were associated with hypertension, lacunes, and severe WMH suggesting that these CSVD markers share common substrates. In the Three-City (3C)-Dijon Magnetic Resonance Imaging Study, in addition to the basal ganglia and white matter, PVS were also observed in the hippocampus and hypothalamus. ${ }^{132}$ In this study, PVS were found in all subjects, with approximately one-third being large ( $>3 \mathrm{~mm}$ ). Men appeared to have more basal ganglia PVS than woman, although this has not been replicated in other studies. ${ }^{133}$ The severity of both basal ganglia and white matter PVS correlated with increasing age. ${ }^{134}$ With increasing WMH volumes and lacunes, the odds of having more severe PVS in the basal ganglia was higher than in white matter.

While several of these studies employ $3 \mathrm{~mm}$ as a size cutoff to distinguish PVS from lacunes, in imaging-pathological correlation studies, an absolute cutoff size has not been established. ${ }^{135}$ PVS above this size cutoff (termed large PVS) may actually be common and were found in approximately one-sixth of the subjects in the AGES-Reykjavik Study. ${ }^{17,136}$ The majority of these large PVS were located in the basal ganglia and only a small fraction of subjects had exclusively white matter PVS. After controlling for age and sex, the presence of these deep large PVS was associated with silent subcortical infarcts and WMH progression. CMB were associated with both deep and white matter large PVS. The concurrent presence of PVS and other markers of CSVD suggests that there are common underlying mechanisms at play.

Although their significance in either healthy or diseased populations is not well understood, the presence of PVS may confer an increased risk of cognitive decline. In one small study, higher numbers of basal ganglia and centrum semiovale PVS were associated with poor performance on neuropsychological testing. ${ }^{137}$ Independent of other cerebrovascular risk factors, large PVS (>3 mm) were associated with poor processing speeds as well as a four-fold increase in VaD risk, but not Alzheimer's dementia (AD) or all-cause dementia risk. ${ }^{136}$ This is consistent with previous studies that observed PVS in higher frequencies in patients with $\mathrm{VaD}$ compared to AD. ${ }^{138,139}$ Furthermore, in another population-based study of elderly nondemented subjects, ${ }^{140}$ patients with the highest degree of both white matter and basal ganglia PVS were most likely to develop dementia over a 4-year period.

\section{Cortical superficial siderosis}

cSS are chronic hemorrhagic products that lie under the pia mater or in the subarachnoid space and are due to a variety of causes including small vascular malformations or CAA. ${ }^{20}$ They are best visualized on paramagnetic MRI sequences given their hemosiderin composition, and appear as a linear hypointensity over the cortex.

In the RS, cSS were found in $0.7 \%$ of individuals, all of which had lobar CMB. ${ }^{141}$ In these individuals, CSS was located near regions of lobar CMB (frontal and occipital areas). In the most recent Rotterdam data, the prevalence of cSS was $0.4 \%$ $(n=3,401) .{ }^{142}$ These 15 individuals had concurrent CMB, the majority (80\%) of which were located in lobar regions. In the 1,425 individuals who received a second MRI at 3 years, two subjects developed new CSS, one of which also developed a new lobar CMB. Of the seven that had baseline CSS, four showed progres- 
sion of cSS on a follow-up scan. These individuals had several lobar CMB on baseline scans ranging from 7 to $130 \mathrm{CMB}$.

In another population-based study $(n=1,412)^{143}$ of individuals aged 50 to 89 (of which a portion had dementia or mild cognitive impairment $\left.{ }^{144}\right)$, using data from the Mayo Clinic Study of Aging, 13 subjects (0.9\%) were found to have cSS. Unlike the RS, only about one-fifth of these patients had concurrent $\mathrm{CMB}$, a finding which is consistent with other reports. ${ }^{145}$ While the presence of the ApoE $\varepsilon 4$ allele did not influence cSS burden, subjects with cSS were more likely to have the presence of the APOE $\varepsilon 2$ allele, which is associated with CAA. ${ }^{146}$ In a subset of patients who underwent Pittsburgh compound $B(\mathrm{PiB})$ positron emission tomographic scans, those with cSS were more likely to be $\mathrm{PiB}$ positive (suggestive of high $\beta$-amyloid burden). Two patients with disseminated cSS had follow-up scans which demonstrated progression of both cSS and CMB. Although small numbers of subjects had both PiB and APOE data, these results suggest that CSS is intimately associated with CAA. Collectively, these findings suggest that CSS may be a marker of CAA-related CSVD rather than hypertensive arteriopathy. cSS is likely a rare finding in healthy populations but is probably exclusively related to coincident CAA pathology when it is found.

\section{Cerebral microinfarcts}

$\mathrm{CMI}$ are microscopic, presumed ischemic infarcts, mostly identified on pathological analysis, but can be seen on 7T MRI studies, and occasionally on 3T studies. ${ }^{147-150}$ Given their ability to escape detection using standard neuroimaging protocols (1.5T MRI), CMI have not been evaluated extensively in healthy individuals. Because their small size (average of 0.2 to $1 \mathrm{~mm}$ in diameter) is below the spatial resolution $\left(1 \mathrm{~mm}^{3}\right)$ for most conventional MRI field strengths, higher strength MRI machines are needed to visualized them. ${ }^{17,1151-153}$ While most of the available data on $\mathrm{CMI}$ has come through post-mortem analysis by 7T MRI, recently, several groups have reported the ability to detect these lesions on 3T MRI in vivo. ${ }^{149,150,154-156}$ However, the sensitivity of detection of $3 \mathrm{~T}$ is limited compared to $7 \mathrm{~T}_{1}^{149}$ and can only detect "large" CMI ( 1 to $3 \mathrm{~mm}$; whereas $7 \mathrm{~T}$ can detect $\mathrm{CMI}<1 \mathrm{~mm}$ ). ${ }^{152}$ As in vivo detection of $\mathrm{CMl}$ is relatively recent, it has not been incorporated into STRIVE definitions, and there have been no consensus definitions established. In some studies, ${ }^{149,150} \mathrm{CMI}$ have been defined on $3 \mathrm{~T} \mathrm{MRI}$ as hypointense on T1-weighted images, hyperintense or isointense on FLAIR and T2-weighted images, distinct from PVS, $<5 \mathrm{~mm}$ in maximum diameter, and perpendicular to the cortical surface.

In patients presenting to a memory clinic in Singapore, the prevalence of $\mathrm{CMI}$ determined by $3 \mathrm{~T}$ MRI was $32 \% .{ }^{149}$ The presence of CMI was associated with hyperlipidemia, history of stroke, and cardiovascular disease (even after controlling for macroinfarcts). Furthermore, the presence of cortical CMI was associated with executive dysfunction as well as lower scores on neurocognitive testing with relative sparing of areas involved in subcortical disease (attention and visuomotor speed). Not surprisingly, patients with cortical CMI were more likely to be diagnosed with $\mathrm{VaD}$ than those without $\mathrm{CMI}$, although previous reports have indicated that the prevalence of individuals with $C M I$ was relatively the same between $A D$ patients and non-demented controls. ${ }^{153,157} \mathrm{CMI}$ were associated with both deep and lobar $\mathrm{CMB}$, increased WMH burden, and small brain volumes. Even after adjusting for $\mathrm{WMH}, \mathrm{CMB}$, or macroinfarcts, $\mathrm{CMI}$ were independently associated with $\mathrm{VCl} .{ }^{149}$ Furthermore, $\mathrm{CMI}$ were associated with cortical and subcortical macroinfarcts (and were not always restricted to the hemisphere of the infarct). CMI were also associated with intracranial stenosis of the vessel supplying the affected territory. These findings have been reproduced in stroke patients, in which it was determined that internal carotid artery stenosis was an independent risk factor for the development of CMI, and CMI development was associated with higher stroke recurrence rates. ${ }^{158}$ Overall, this study of memory clinic patients suggests that $\mathrm{CMI}$ are a common finding in elderly patients with cognitive dysfunction and is in accordance with other population-based neuropathological studies. ${ }^{159}$ This study also reported hyperlipidemia as a risk factor for CMI whereas previous population-based autopsy studies identified hypertension as the causative agent. ${ }^{160,161}$ Interestingly, in another analysis using this Singapore cohort, ${ }_{1}^{162} 29 \%$ of subjects exhibited CMI on 3T MRI. These patients had an increased frequency of hypertension, hyperlipidemia, cardiac disease, and were found to have higher levels of subclinical cardiac biomarkers including N-terminal pro-brain natriuretic peptide (nT-proB$\mathrm{NP}$ ) and high-sensitivity cardiac troponin T (hs-cTnT) (after adjusting for age, sex, cardiac disease, and other cerebrovascular risk factors). In addition, there was an association between atrial fibrillation, ischemic heart disease, and congestive heart failure with cortical CMI. Indeed, in one neuropathological study, it was suggested that CMI may be caused by microemboli. ${ }^{163}$ The constellations of these associations including hyperlipidemia, intracranial atherosclerosis, and cardiac disease suggests that $\mathrm{CMI}$ have a heterogenous etiology that arises from shared pathways of CSVD, cardioembolism, and large vessel stenosis.

In another large, population-based study that recruited participants from the multiethnic Epidemiology of Dementia in Singapore Study (EDIS; $n=1,598), 6.3 \%$ exhibited at least one CMI. ${ }^{164,165}$ The majority of these were located in the parietal 
lobes (42\%), and to a lesser extent, frontal (21\%), occipital $(12 \%)$, and temporal lobes consistent with one earlier small study using $7 \mathrm{~T} \mathrm{MRI}{ }^{157}$ The presence of other markers of CSVD (including lacunar infarcts, WMH, and CMB) as well as macroinfarcts and intracranial stenosis was greater in patients with CMI. Risk factors associated with CMI were increasing age, Malay ethnicity, hypertension, diabetes, and history of stroke. Although not consistent with previous reports, ${ }_{1}^{166,167}$ the association of CMI with diabetes suggests that $\mathrm{CMI}$ may also be caused by microatheromatous disease at penetrating capillaries. While it was not significant in this study, cigarette smoking has been associated with the presence of $\mathrm{CMI}$ in other studies. ${ }^{168}$ In addition to cerebrovascular risk factors, subjects with $\mathrm{CMI}$ were more likely to have moderate cognitive impairment and dementia. ${ }^{165}$ Furthermore, the presence of $\mathrm{CMI}$ was associated with poor performance on neuropsychological testing even after controlling for lacunar infarcts. Collectively, $\mathrm{CMI}$ are independently associated with neurocognitive impairment as has been observed in neuropathological studies. ${ }^{169}$

Very few studies have examined whether the anatomical location of CMl suggests different risk factors or underlying pathologies. In one recent large population-based neuropathological study of elderly community dwelling individuals $(n=1,066){ }^{170-172}$ $\mathrm{CMI}$ were found in one-third of subjects. The odds of having one or more $\mathrm{CMI}$ were increased in patients with atherosclerosis, arteriolosclerosis, and CAA. However, in a subgroup analysis, only atherosclerosis and arteriolosclerosis were associated with subcortical CMI, whereas CAA was associated with cortical CMI. Similar to other biomarkers, cortical CMI may be associated with CAA pathology whereas subcortical CMI may be due to other mechanisms such as hypertension.

\section{Screening for CSVD}

The major clinical features and associated risk factors for CSVD biomarkers are summarized below (Table 3). Currently, screening of asymptomatic individuals for CSVD is not recommended. ${ }^{173}$ The major reasons MRIs are not performed in healthy populations is cost and lack of intervenable measures if asymptomatic CSVD is identified. However, more cost-effective methods of screening for CSVD may be able to select at-risk patients, especially those in high-risk populations, such as women or African Americans. These initial studies, if abnormal, can prompt further testing including MRI.

In patients that have received a brain MRI, a total SVD score can be calculated to assess the total burden of CSVD. ${ }^{174}$ This visually rated score (ranging from 0 to 4 ) incorporates $\mathrm{WMH}_{\text {, }}$ lacunes, CMB, and PVS, and reflects the amount of brain injury attributable to CSVD. ${ }^{175}$ Not surprisingly, hypertension, age, male gender, and smoking are associated with higher SVD scores, highlighting the concept of shared underlying pathogenic mechanisms. Although it has not been widely adopted in clinical practice, this score can assist in stratifying patients at risk for ischemic stroke ${ }^{176}$ or cognitive impairment. Furthermore, it can serve as a surrogate combined marker for CSVD in clinical trials focused on secondary prevention. ${ }^{174}$

In cross-sectional population-based studies, numerous biomarkers such as fibrinogen, $\mathrm{C}$-reactive protein (CRP), interleukin-6, neurofilament light chain, homocysteine, and D-dimer have been associated with the presence of CSVD markers such as WMH, lacunes, and PVS. ${ }^{177-179}$ In two longitudinal populationbased studies, only intercellular adhesion molecule 1 (ICAM-1) and CRP have been found to be associated with WMH progres-

Table 3. Summary of biomarkers

\begin{tabular}{|c|c|c|c|c|c|}
\hline Neuroimaging markers & Pathological correlate & MRI appearance & Risk factors & Associated CSVD subtype & Sequelae \\
\hline WMH & $\begin{array}{l}\text { Chronically hypoperfused } \\
\text { brain parenchyma }\end{array}$ & $\begin{array}{l}\text { Hyperintense on T2 and FLAIR, hypoin- } \\
\text { tense on T1 (variable size) }\end{array}$ & $\begin{array}{l}\text { Age, smoking, } \\
\text { hypertension }\end{array}$ & HTN-CSVD, CAA & $\mathrm{IS}, \mathrm{ICH}, \mathrm{VaD}$ \\
\hline Lacunes & $\begin{array}{l}\text { Chronic fluid-filled end- } \\
\text { product of small subcorti- } \\
\text { cal infarcts }\end{array}$ & $\begin{array}{l}\text { Central hypointensity with surrounding } \\
\text { rim of hyperintensity on FLAIR ( } 3 \text { to } 15 \\
\mathrm{~mm} \text { ) }\end{array}$ & $\begin{array}{l}\text { Age, smoking, } \\
\text { hypertension }\end{array}$ & HTN-CSVD, CAA & $\mathrm{IS}, \mathrm{ICH}, \mathrm{VaD}$ \\
\hline $\mathrm{CMB}$ & $\begin{array}{l}\text { Foci of hemosiderin-laden } \\
\text { macrophages }\end{array}$ & $\begin{array}{l}\text { Round/oval shaped signal void ( } \leq 10 \mathrm{~mm}) \\
\text { with blooming artifact on } \mathrm{T} 2^{*}, \mathrm{GRE}, \mathrm{SWI}\end{array}$ & $\begin{array}{l}\text { Age, smoking, } \\
\text { hypertension }\end{array}$ & HTN-CSVD, CAA & $\mathrm{IS}, \mathrm{ICH}, \mathrm{VaD}$ \\
\hline PVS & $\begin{array}{l}\text { Interstitial fluid-filled spaces } \\
\text { surrounding blood vessels }\end{array}$ & $\begin{array}{l}\text { Linear cavitation without hyperintense T2 } \\
\text { rim on FLAIR }(<3 \mathrm{~mm})\end{array}$ & Hypertension & HTN-CSVD, CAA & $\mathrm{VaD}$ \\
\hline cSS & $\begin{array}{l}\text { Chronic hemorrhagic prod- } \\
\text { ucts underlying pia mater }\end{array}$ & $\begin{array}{l}\text { Curvilinear hypointensity that follows gy- } \\
\text { ral surface on T2* GRE, SWI }\end{array}$ & Unknown & CAA & $\mathrm{ICH}$ \\
\hline CMI & $\begin{array}{l}\text { Microscopic ischemic in- } \\
\text { farcts }\end{array}$ & $\begin{array}{l}\text { Hypointense on T1, hyperintense on T2/ } \\
\text { FLAIR }(<5 \mathrm{~mm})\end{array}$ & Heterogenous & HTN-CSVD, CAA & $\mathrm{VaD}$ \\
\hline
\end{tabular}

MRI, magnetic resonance imaging; CSVD, cerebral small vessel disease; WMH, white matter hyperintensity; FLAIR, fluid attenuated inversion recovery; HTN, hypertensive; CAA, cerebral amyloid angiopathy; IS, ischemic stroke; ICH, intracerebral hemorrhage; VaD, vascular dementia; CMB, cerebral microbleed; GRE, gradient echo; SWI, susceptibility-weighted imaging; PVS, perivascular spaces; cSS, cortical superficial siderosis; CMI, cerebral microinfarcts. 
sion. ${ }^{180,181}$ However, given that there have been conflicting results in these studies, ${ }^{182-185}$ the use of biomarkers for routine screening of CSVD is not recommended in healthy populations. These markers may be incidental, and their significance and progression remain unclear. Several of these biomarkers, such as homocysteine are not entirely specific for CSVD and can be elevated in other stroke subtypes. ${ }^{186}$ Moreover, interpretation of cut off values and heterogeneity among studies confounds interpretation of results. Future efforts should be aimed at identifying specific markers for asymptomatic CSVD, markers that represent accelerated CSVD progression, and markers that predict conversion from asymptomatic to symptomatic CSVD.

\section{Treatment and future directions}

It remains unclear how to best identify patients with asymptomatic CSVD. Furthermore, it is unclear whether treatment of CSVD at an asymptomatic disease stage is necessary or beneficial. ${ }^{173}$ Perhaps the most available data comes from studies on WMH in community-dwelling individuals. As hypertension seems to play the biggest role in CSVD pathogenesis, it is not surprising that the majority of these studies focus on hypertension reduction. Early trials have demonstrated higher WMH volumes in patients with uncontrolled hypertension compared to those receiving antihypertensive medications. ${ }^{187,188}$ Furthermore, several trials have demonstrated reduced WMH progression with BP reduction therapy, ${ }_{1}^{189-193}$ although these results were not replicated in all studies. ${ }^{194}$ When these trials were analyzed in a recent meta-analysis, ${ }^{193}$ less WMH progression was observed in subjects taking antihypertensive medications. The optimal timing for usage of these antihypertensives remains unclear, but presumably, earlier intervention may be more beneficial. Whether antihypertensive medications have similar effects on other CSVD biomarkers in unknown.

In addition to antihypertensives, other studies have examined statin usage, although very few population-based studies demonstrate an association of hyperlipidemia with CSVD. Three studies have demonstrated reductions in WMH with lipid-lowering drugs, ${ }^{195-197}$ while other studies did not show any benefit. ${ }^{198,199}$ Although the association between diabetes and CSVD is controversial, ${ }^{200,201}$ hyperglycemia was shown to influence WMH progression in one study. ${ }^{72}$ No studies, however, have evaluated glycemic control on WMH reduction. Lastly, in one meta-analysis, half of the studies demonstrated WMH reduction with exercise, but the other half did not. ${ }^{202}$

Although antiplatelet agents have been extensively evaluated in the primary and secondary prevention of patients with lacunar stroke, there have been few studies examining the cerebro- vascular effects of antiplatelet agents in healthy populations. In one small study, healthy subjects who underwent MRI screening for WMH were given antiplatelet therapy. ${ }^{203,204}$ In a follow-up MRI study 5 years later, there was no difference in deep or periventricular WMH progression among patients taking antiplatelet agents. Given the small observational nature of this study, larger studies will need to be performed to fully elucidate the effects of antiplatelet therapy on CSVD prevention. However, it should be noted that these therapies may be counterbalanced by an increased risk of CMB (and subsequent ICH). ${ }^{205,206}$

Some patients with CSVD may exhibit minimal or no clinical symptoms while other patients develop stroke, cognitive impairment, and other long-term morbidity. ${ }^{6,22}$ Early detection of clinically significant CSVD is particularly difficult for reasons including (1) utility of screening in the general population and (2) lack of full understanding of the significance of CSVD biomarkers. ${ }^{207}$ Part of the challenge in developing a validated brain biomarker for CSVD is the complex pathways that underlie the disease. Risk prediction models to select populations at higher risk are urgently needed.

\section{Disclosure}

The authors have no financial conflicts of interest.

\section{Acknowledgments}

This work was supported by the National Institutes of Health (R01AG047975, R01AG026484, P50AG005134, and K23AG028 72605 to $A V$ and R25NS065743 to RWR).

\section{References}

1. Berkhemer OA, Fransen PS, Beumer D, van den Berg LA, Lings-

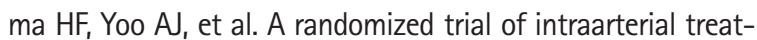
ment for acute ischemic stroke. N Engl J Med 2015;372:11-20.

2. Campbell BC, Mitchell PJ, Kleinig TJ, Dewey HM, Churilov L, Yassi $\mathrm{N}$, et al. Endovascular therapy for ischemic stroke with perfusion-imaging selection. N Engl J Med 2015;372:1009-1018.

3. Jovin TG, Chamorro A, Cobo E, de Miquel MA, Molina CA, Rovira A, et al. Thrombectomy within 8 hours after symptom onset in ischemic stroke. N Eng/ J Med 2015;372:2296-2306.

4. Saver JL, Goyal M, Bonafe A, Diener HC, Levy El, Pereira VM, et al. Stent-retriever thrombectomy after intravenous t-PA vs. t-PA alone in stroke. N Eng/ J Med 2015;372:2285-2295.

5. Bracard S, Ducrocq X, Mas JL, Soudant M, Oppenheim C, Moulin T, et al. Mechanical thrombectomy after intravenous alteplase versus alteplase alone after stroke (THRACE): a ran- 
domised controlled trial. Lancet Neurol 2016;15:1138-1147.

6. Charidimou A, Pantoni $L$, Love $S$. The concept of sporadic cerebral small vessel disease: a road map on key definitions and current concepts. Int J Stroke 2016;11:6-18.

7. Pantoni L. Cerebral small vessel disease: from pathogenesis and clinical characteristics to therapeutic challenges. Lancet Neurol 2010;9:689-701.

8. Whitman GT, Tang Y, Lin A, Baloh RW. A prospective study of cerebral white matter abnormalities in older people with gait dysfunction. Neurology 2001;57:990-994.

9. Vermeer SE, Prins ND, den Heijer T, Hofman A, Koudstaal PJ, Breteler MM. Silent brain infarcts and the risk of dementia and cognitive decline. N Engl J Med 2003;348:1215-1222.

10. Vermeer SE, Longstreth WT Jr, Koudstaal PJ. Silent brain infarcts: a systematic review. Lancet Neurol 2007;6:611-619.

11. Russo E, Leo A, Scicchitano F, Donato A, Ferlazzo E, Gasparini $S$, et al. Cerebral small vessel disease predisposes to temporal lobe epilepsy in spontaneously hypertensive rats. Brain Res Bull 2017;130:245-250.

12. de Groot JC, de Leeuw FE, Oudkerk M, van Gijn J, Hofman A, Jolles J, et al. Cerebral white matter lesions and cognitive function: the Rotterdam Scan Study. Ann Neurol 2000;47: 145-151.

13. van der Holst HM, van Uden IW, Tuladhar AM, de Laat KF, van Norden AG, Norris DG, et al. Cerebral small vessel disease and incident parkinsonism: The RUN DMC study. Neurology 2015;85:1569-1577.

14. Wardlaw JM, Smith C, Dichgans M. Mechanisms of sporadic cerebral small vessel disease: insights from neuroimaging. Lancet Neurol 2013;12:483-497.

15. Søndergaard CB, Nielsen JE, Hansen CK, Christensen H. Hereditary cerebral small vessel disease and stroke. Clin Neurol Neurosurg 2017;155:45-57.

16. Choi JC. Genetics of cerebral small vessel disease. J Stroke 2015;17:7-16.

17. Wermer MJH, Greenberg SM. The growing clinical spectrum of cerebral amyloid angiopathy. Curr Opin Neurol 2018;31: 28-35.

18. Charidimou A, Boulouis G, Gurol ME, Ayata C, Bacskai BJ, Frosch MP, et al. Emerging concepts in sporadic cerebral amyloid angiopathy. Brain 2017;140:1829-1850.

19. Greenberg SM. Small vessels, big problems. N Engl J Med 2006;354:1451-1453.

20. Wardlaw JM, Smith EE, Biessels GJ, Cordonnier C, Fazekas F, Frayne $R$, et al. Neuroimaging standards for research into small vessel disease and its contribution to ageing and neurodegeneration. Lancet Neurol 2013;12:822-838.

21. Price TR, Manolio TA, Kronmal RA, Kittner SJ, Yue NC, Robbins
$J$, et al. Silent brain infarction on magnetic resonance imaging and neurological abnormalities in community-dwelling older adults. The Cardiovascular Health Study. CHS Collaborative Research Group. Stroke 1997;28:1158-1164.

22. Leary MC, Saver JL. Annual incidence of first silent stroke in the United States: a preliminary estimate. Cerebrovasc Dis 2003;16:280-285.

23. Westover MB, Bianchi MT, Yang C, Schneider JA, Greenberg SM. Estimating cerebral microinfarct burden from autopsy samples. Neurology 2013;80:1365-1369.

24. Auriel E, Westover MB, Bianchi MT, Reijmer Y, MartinezRamirez S, Ni J, et al. Estimating total cerebral microinfarct burden from diffusion-weighted imaging. Stroke 2015;46: 2129-2135.

25. van Veluw SJ, Shih AY, Smith EE, Chen C, Schneider JA, Wardlaw JM, et al. Detection, risk factors, and functional consequences of cerebral microinfarcts. Lancet Neurol 2017; 16:730-740.

26. Feng $C$, Bai $X, X u Y$, Hua $T$, Liu $X Y$. The 'silence' of silent brain infarctions may be related to chronic ischemic preconditioning and nonstrategic locations rather than to a small infarction size. Clinics (Sao Paulo) 2013;68:365-369.

27. Shi Y, Wardlaw JM. Update on cerebral small vessel disease: a dynamic whole-brain disease. Stroke Vasc Neurol 2016;1:8392.

28. van Leijsen EMC, de Leeuw FE, Tuladhar AM. Disease progression and regression in sporadic small vessel disease-insights from neuroimaging. Clin Sci (Lond) 2017;131:1191-1206.

29. Hachinski VC, Potter P, Merskey H. Leuko-araiosis. Arch Neurol 1987;44:21-23.

30. Pantoni L, Garcia JH. The significance of cerebral white matter abnormalities 100 years after Binswanger's report: a review. Stroke 1995;26:1293-1301.

31. Pantoni $L$, Garcia JH. Pathogenesis of leukoaraiosis: a review. Stroke 1997;28:652-659.

32. Debette $\mathrm{S}$, Markus HS. The clinical importance of white matter hyperintensities on brain magnetic resonance imaging: systematic review and meta-analysis. BMJ 2010;341:c3666.

33. Topakian R, Barrick TR, Howe FA, Markus HS. Blood-brain barrier permeability is increased in normal-appearing white matter in patients with lacunar stroke and leucoaraiosis. $J$ Neurol Neurosurg Psychiatry 2010;81:192-197.

34. Wardlaw JM, Valdés Hernández MC, Muñoz-Maniega S. What are white matter hyperintensities made of? Relevance to vascular cognitive impairment. J Am Heart Assoc 2015;4:001140.

35. Longstreth WT Jr, Manolio TA, Arnold A, Burke GL, Bryan N, Jungreis $C A$, et al. Clinical correlates of white matter findings on cranial magnetic resonance imaging of 3301 elderly people. 
The Cardiovascular Health Study. Stroke 1996;27:1274-1282.

36. Longstreth WT Jr, Arnold AM, Beauchamp NJ Jr, Manolio TA, Lefkowitz $D$, Jungreis $C$, et al. Incidence, manifestations, and predictors of worsening white matter on serial cranial magnetic resonance imaging in the elderly: the Cardiovascular Health Study. Stroke 2005;36:56-61.

37. de Leeuw FE, de Groot JC, Achten E, Oudkerk M, Ramos LM, Heijboer $R$, et al. Prevalence of cerebral white matter lesions in elderly people: a population based magnetic resonance imaging study. The Rotterdam Scan Study. J Neurol Neurosurg Psychiatry 2001;70:9-14.

38. van Dijk EJ, Prins ND, Vrooman HA, Hofman A, Koudstaal PJ, Breteler MM. Progression of cerebral small vessel disease in relation to risk factors and cognitive consequences: Rotterdam Scan study. Stroke 2008;39:2712-2719.

39. Liao D, Cooper L, Cai J, Toole JF, Bryan NR, Hutchinson RG, et al. Presence and severity of cerebral white matter lesions and hypertension, its treatment, and its control. The ARIC Study. Atherosclerosis Risk in Communities Study. Stroke 1996;27: 2262-2270.

40. Schmidt R, Fazekas F, Kapeller P, Schmidt H, Hartung HP. MRI white matter hyperintensities: three-year follow-up of the Austrian Stroke Prevention Study. Neurology 1999;53:132139.

41. Schmidt R, Ropele S, Enzinger C, Petrovic K, Smith S, Schmidt

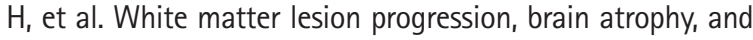
cognitive decline: the Austrian Stroke Prevention Study. Ann Neurol 2005;58:610-616.

42. Power MC, Deal JA, Sharrett AR, Jack CR Jr, Knopman D, Mosley $\mathrm{TH}$, et al. Smoking and white matter hyperintensity progression: the ARIC-MRI Study. Neurology 2015;84:841-848.

43. Jeerakathil T, Wolf PA, Beiser A, Massaro J, Seshadri S, D'Agostino RB, et al. Stroke risk profile predicts white matter hyperintensity volume: the Framingham Study. Stroke 2004; 35:1857-1861.

44. Debette $S$, Seshadri S, Beiser A, Au R, Himali JJ, Palumbo C, et al. Midlife vascular risk factor exposure accelerates structural brain aging and cognitive decline. Neurology 2011;77: 461-468.

45. Schmidt R, Petrovic K, Ropele S, Enzinger C, Fazekas F. Progression of leukoaraiosis and cognition. Stroke 2007;38: 2619-2625.

46. Bokura H, Kobayashi S, Yamaguchi S, lijima K, Nagai A, Toyoda $G$, et al. Silent brain infarction and subcortical white matter lesions increase the risk of stroke and mortality: a prospective cohort study. J Stroke Cerebrovasc Dis 2006;15:57-63.

47. Fried LP, Borhani NO, Enright P, Furberg CD, Gardin JM, Kronmal RA, et al. The Cardiovascular Health Study: design and rationale. Ann Epidemiol 1991;1:263-276.

48. Tell GS, Fried LP, Hermanson B, Manolio TA, Newman AB, Borhani NO. Recruitment of adults 65 years and older as participants in the Cardiovascular Health Study. Ann Epidemiol 1993;3:358-366.

49. Price TR, Psaty B, O'Leary D, Burke G, Gardin J. Assessment of cerebrovascular disease in the Cardiovascular Health Study. Ann Epidemiol 1993;3:504-507.

50. Manolio TA, Kronmal RA, Burke GL, Poirier V, O'Leary DH, Gardin JM, et al. Magnetic resonance abnormalities and cardiovascular disease in older adults. The Cardiovascular Health Study. Stroke 1994;25:318-327.

51. Longstreth WT Jr, Bernick C, Manolio TA, Bryan N, Jungreis $C A$, Price TR. Lacunar infarcts defined by magnetic resonance imaging of 3660 elderly people: the Cardiovascular Health Study. Arch Neurol 1998;55:1217-1225.

52. Bernick C, Kuller L, Dulberg C, Longstreth WT Jr, Manolio T, Beauchamp N, et al. Silent MRI infarcts and the risk of future stroke: the Cardiovascular Health Study. Neurology 2001;57: 1222-1229.

53. Longstreth WT Jr, Dulberg C, Manolio TA, Lewis MR, Beauchamp NJ Jr, O'Leary $D$, et al. Incidence, manifestations, and predictors of brain infarcts defined by serial cranial magnetic resonance imaging in the elderly: the Cardiovascular Health Study. Stroke 2002;33:2376-2382.

54. Hofman A, Grobbee DE, de Jong PT, van den Ouweland FA. Determinants of disease and disability in the elderly: the Rotterdam Elderly Study. Eur J Epidemiol 1991;7:403-422.

55. van Dijk EJ, Prins ND, Vermeer SE, Koudstaal PJ, Breteler MM. Frequency of white matter lesions and silent lacunar infarcts. J Neural Transm Suppl 2002;62:25-39.

56. Vermeer SE, Koudstaal PJ, Oudkerk M, Hofman A, Breteler $M M$. Prevalence and risk factors of silent brain infarcts in the population-based Rotterdam Scan Study. Stroke 2002;33:2125.

57. Vernooij MW, Ikram MA, Tanghe HL, Vincent AJ, Hofman A, Krestin GP, et al. Incidental findings on brain MRI in the general population. N Engl J Med 2007;357:1821-1828.

58. Poels MM, Zaccai K, Verwoert GC, Vernooij MW, Hofman A, van der Lugt $A$, et al. Arterial stiffness and cerebral small vessel disease: the Rotterdam Scan Study. Stroke 2012;43: 2637-2642.

59. Shepherd J, Blauw GJ, Murphy MB, Cobbe SM, Bollen EL, Buckley BM, et al. The design of a prospective study of Pravastatin in the Elderly at Risk (PROSPER). PROSPER Study Group. PROspective Study of Pravastatin in the Elderly at Risk. Am J Cardiol 1999;84:1192-1197.

60. van den Heuvel DM, Admiraal-Behloul F, ten Dam VH, Olof- 
sen $\mathrm{H}_{1}$ Bollen EL, Murray HM, et al. Different progression rates for deep white matter hyperintensities in elderly men and women. Neurology 2004;63:1699-1701.

61. The ARIC investigators. The Atherosclerosis Risk in Communities (ARIC) study: design and objectives. Am J Epidemiol 1989;129:687-702.

62. Mosley TH Jr, Knopman DS, Catellier DJ, Bryan N, Hutchinson $R G$, Grothues CA, et al. Cerebral MRI findings and cognitive functioning: the Atherosclerosis Risk in Communities study. Neurology 2005;64:2056-2062.

63. Liao D, Cooper L, Cai J, Toole J, Bryan N, Burke G, et al. The prevalence and severity of white matter lesions, their relationship with age, ethnicity, gender, and cardiovascular disease risk factors: the ARIC Study. Neuroepidemiology 1997; 16:149-162.

64. Gottesman RF, Coresh J, Catellier DJ, Sharrett AR, Rose KM, Coker $\mathrm{LH}$, et al. Blood pressure and white-matter disease progression in a biethnic cohort: Atherosclerosis Risk in Communities (ARIC) study. Stroke 2010;41:3-8.

65. Wolma J, Nederkoorn PJ, Goossens A, Vergouwen MD, van Schaik IN, Vermeulen M. Ethnicity a risk factor? The relation between ethnicity and large- and small-vessel disease in White people, Black people, and Asians within a hospitalbased population. Eur J Neurol 2009;16:522-527.

66. Hilal S, Mok V, Youn YC, Wong A, Ikram MK, Chen CL. Prevalence, risk factors and consequences of cerebral small vessel diseases: data from three Asian countries. J Neurol Neurosurg Psychiatry 2017;88:669-674.

67. Sudre $\mathrm{CH}$, Smith L, Atkinson D, Chaturvedi N, Ourselin S, Bark-

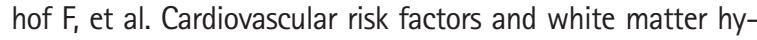
perintensities: difference in susceptibility in south Asians compared with Europeans. J Am Heart Assoc 2018;7:e010533.

68. Han F, Zhai FF, Wang Q, Zhou LX, Ni J, Yao M, et a. Prevalence and risk factors of cerebral small vessel disease in a Chinese population-based sample. J Stroke 2018;20:239-246.

69. van Zagten M, Boiten J, Kessels F, Lodder J. Significant progression of white matter lesions and small deep (lacunar) infarcts in patients with stroke. Arch Neuro/ 1996;53:650-655.

70. Sachdev $P$, Wen $W$, Chen $X$, Brodaty $H$. Progression of white matter hyperintensities in elderly individuals over 3 years. Neurology 2007;68:214-222.

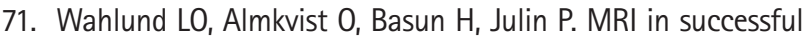
aging, a 5-year follow-up study from the eighth to ninth decade of life. Magn Reson Imaging 1996;14:601-608.

72. Gouw AA, van der Flier WM, Fazekas F, van Straaten EC, Pantoni $L_{1}$ Poggesi A, et al. Progression of white matter hyperintensities and incidence of new lacunes over a 3-year period: the Leukoaraiosis and Disability study. Stroke 2008;39:1414-
1420.

73. Taylor WD, MacFall JR, Provenzale JM, Payne ME, McQuoid $D R$, Steffens DC, et al. Serial MR imaging of volumes of hyperintense white matter lesions in elderly patients: correlation with vascular risk factors. AJR Am J Roentgenol 2003; 181:571-576.

74. Kuller LH, Longstreth WT Jr, Arnold AM, Bernick C, Bryan RN, Beauchamp NJ Jr, et al. White matter hyperintensity on cranial magnetic resonance imaging: a predictor of stroke. Stroke 2004;35:1821-1825.

75. Schmidt R, Fazekas F, Enzinger C, Ropele S, Kapeller $P$, Schmidt $H$. Risk factors and progression of small vessel disease-related cerebral abnormalities. J Neural Transm Supp/ 2002;62:47-52.

76. Schmidt R, Enzinger C, Ropele S, Schmidt H, Fazekas F; Austrian Stroke Prevention Study. Progression of cerebral white matter lesions: 6-year results of the Austrian Stroke Prevention Study. Lancet 2003;361:2046-2048.

77. Verhaaren BF, Vernooij MW, de Boer $R$, Hofman A, Niessen WJ, van der Lugt $A$, et al. High blood pressure and cerebral white matter lesion progression in the general population. Hypertension 2013;61:1354-1359.

78. Debette S, Beiser A, DeCarli C, Au R, Himali JJ, Kelly-Hayes M, et al. Association of MRI markers of vascular brain injury with incident stroke, mild cognitive impairment, dementia, and mortality: the Framingham Offspring Study. Stroke 2010;41: 600-606

79. Ikram MA, Vernooij MW, Vrooman HA, Hofman A, Breteler MM. Brain tissue volumes and small vessel disease in relation to the risk of mortality. Neurobiol Aging 2009;30:450-456.

80. Kerber KA, Whitman GT, Brown DL, Baloh RW. Increased risk of death in community-dwelling older people with white matter hyperintensities on MRI. J Neurol Sci 2006;250:33-38.

81. Buyck JF, Dufouil C, Mazoyer B, Maillard P, Ducimetière $P$, Alpérovitch $A_{1}$ et al. Cerebral white matter lesions are associated with the risk of stroke but not with other vascular events: the 3-City Dijon Study. Stroke 2009;40:2327-2331.

82. Tully PJ, Debette S, Mazoyer B, Tzourio C. White matter lesions are associated with specific depressive symptom trajectories among incident depression and dementia populations: three-city Dijon MRI study. Am J Geriatr Psychiatry 2017;25:1311-1321.

83. Smith EE, Egorova S, Blacker D, Killiany RJ, Muzikansky A, Dickerson $\mathrm{BC}$, et al. Magnetic resonance imaging white matter hyperintensities and brain volume in the prediction of mild cognitive impairment and dementia. Arch Neurol 2008; 65:94-100.

84. Silbert LC, Howieson DB, Dodge $H$, Kaye JA. Cognitive impair- 
ment risk: white matter hyperintensity progression matters. Neurology 2009;73:120-125.

85. van den Heuvel DM, ten Dam VH, de Craen AJ, AdmiraalBehloul $\mathrm{F}$, Olofsen $\mathrm{H}$, Bollen $\mathrm{EL}$, et al. Increase in periventricular white matter hyperintensities parallels decline in mental processing speed in a non-demented elderly population. $J$ Neurol Neurosurg Psychiatry 2006;77:149-153.

86. Corder EH, Saunders AM, Strittmatter WJ, Schmechel DE, Gaskell PC, Small GW, et al. Gene dose of apolipoprotein E type 4 allele and the risk of Alzheimer's disease in late onset families. Science 1993;261:921-923.

87. Heise V, Filippini N, Ebmeier KP, Mackay CE. The APOE $\varepsilon 4$ allele modulates brain white matter integrity in healthy adults. Mol Psychiatry 2011;16:908-916.

88. Sudre $\mathrm{CH}_{1}$ Cardoso MJ, Frost C, Barnes J, Barkhof F, Fox N, et al. APOE $\varepsilon 4$ status is associated with white matter hyperintensities volume accumulation rate independent of $A D$ diagnosis. Neurobiol Aging 2017;53:67-75.

89. Cox SR, Ritchie SJ, Dickie DA, Pattie A, Royle NA, Corley J, et al. Interaction of APOE e4 and poor glycemic control predicts white matter hyperintensity growth from 73 to 76 . Neurobiol Aging 2017;54:54-58.

90. Prins ND, van Dijk EJ, den Heijer T, Vermeer SE, Koudstaal PJ, Oudkerk $\mathrm{M}$, et al. Cerebral white matter lesions and the risk of dementia. Arch Neurol 2004;61:1531-1534.

91. Fisher CM. Lacunar strokes and infarcts: a review. Neurology 1982;32:871-876.

92. Fisher CM. Lacunes: small, deep cerebral infarcts. Neurology 1965;15:774-784.

93. Kimberly WT, Gilson A, Rost NS, Rosand J, Viswanathan A, Smith $E_{\text {, }}$ et al. Silent ischemic infarcts are associated with hemorrhage burden in cerebral amyloid angiopathy. Neurology 2009;72:1230-1235.

94. Prabhakaran S, Gupta R, Ouyang B, John S, Temes RE, Mohammad $Y$, et al. Acute brain infarcts after spontaneous intracerebral hemorrhage: a diffusion-weighted imaging study. Stroke 2010;41:89-94.

95. Wardlaw JM, Chappell FM, Valdés Hernández MDC, Makin SDJ, Staals J, Shuler K, et al. White matter hyperintensity reduction and outcomes after minor stroke. Neurology 2017;89: 1003-1010.

96. Moreau F, Patel S, Lauzon ML, McCreary CR, Goyal M, Frayne $\mathrm{R}$, et al. Cavitation after acute symptomatic lacunar stroke depends on time, location, and MRI sequence. Stroke 2012; 43:1837-1842.

97. Fanning JP, Wong AA, Fraser JF. The epidemiology of silent brain infarction: a systematic review of population-based cohorts. BMC Med 2014;12:119.
98. Howard G, Wagenknecht LE, Cai J, Cooper L, Kraut MA, Toole JF. Cigarette smoking and other risk factors for silent cerebral infarction in the general population. Stroke 1998;29:913-917.

99. Vermeer SE, Den Heijer T, Koudstaal PJ, Oudkerk M, Hofman A, Breteler $M M$, et al. Incidence and risk factors of silent brain infarcts in the population-based Rotterdam Scan Study. Stroke 2003;34:392-396.

100. Vermeer SE, Hollander M, van Dijk EJ, Hofman A, Koudstaal $P J$, Breteler MM, et al. Silent brain infarcts and white matter lesions increase stroke risk in the general population: the Rotterdam Scan Study. Stroke 2003;34:1126-1129.

101. Greenberg SM, Vernooij MW, Cordonnier C, Viswanathan $A_{1}$ Al-Shahi Salman R, Warach S, et al. Cerebral microbleeds: a guide to detection and interpretation. Lancet Neurol 2009; 8:165-174.

102. Martinez-Ramirez S, Greenberg SM, Viswanathan A. Cerebral microbleeds: overview and implications in cognitive impairment. Alzheimers Res Ther 2014;6:33.

103. Shoamanesh A, Kwok CS, Benavente O. Cerebral microbleeds: histopathological correlation of neuroimaging. Cerebrovasc Dis 2011;32:528-534.

104. Viswanathan A, Chabriat H. Cerebral microhemorrhage. Stroke 2006;37:550-555.

105. Tsushima Y, Tanizaki Y, Aoki J, Endo K. MR detection of microhemorrhages in neurologically healthy adults. Neuroradiology 2002;44:31-36.

106. Poels MM, Vernooij MW, Ikram MA, Hofman A, Krestin GP, van der Lugt $A$, et al. Prevalence and risk factors of cerebral microbleeds: an update of the Rotterdam scan study. Stroke 2010;41:S103-S106.

107. Roob G, Schmidt R, Kapeller P, Lechner A, Hartung HP, Fazekas F. MRI evidence of past cerebral microbleeds in a healthy elderly population. Neurology 1999;52:991-994.

108. Dawber TR, Meadors GF, Moore FE Jr. Epidemiological approaches to heart disease: the Framingham Study. Am J Public Health Nations Health 1951;41:279-281.

109. Kannel WB, Feinleib M, McNamara PM, Garrison RJ, Castelli WP. An investigation of coronary heart disease in families. The Framingham offspring study. Am J Epidemiol 1979;110: 281-290.

110. Sveinbjornsdottir S, Sigurdsson S, Aspelund T, Kjartansson O, Eiriksdottir G, Valtysdottir B, et al. Cerebral microbleeds in the population based AGES-Reykjavik study: prevalence and location. J Neurol Neurosurg Psychiatry 2008;79:1002-1006.

111. Del Brutto VJ, Zambrano M, Mera RM, Del Brutto OH. Population-based study of cerebral microbleeds in stroke-free older adults living in rural Ecuador: The Atahualpa Project. Stroke 2015;46:1984-1986. 
112. de Laat $K F$, van den Berg $H A$, van Norden $A G$, Gons RA, Olde Rikkert MG, de Leeuw FE. Microbleeds are independently related to gait disturbances in elderly individuals with cerebral small vessel disease. Stroke 2011;42:494-497.

113. Mitaki $S$, Nagai A, Oguro $H$, Yamaguchi S. Serum lipid fractions and cerebral microbleeds in a healthy Japanese population. Cerebrovasc Dis 2017;43:186-191.

114. Mok V, Srikanth V, Xiong Y, Phan TG, Moran C, Chu S, et al. Race-ethnicity and cerebral small vessel disease: comparison between Chinese and White populations. Int J Stroke 2014;9 Suppl A100:36-42.

115. Jeerakathil T, Wolf PA, Beiser A, Hald JK, Au R, Kase CS, et al. Cerebral microbleeds: prevalence and associations with cardiovascular risk factors in the Framingham Study. Stroke 2004;35:1831-1835.

116. Vernooij MW, van der Lugt $A$, Ikram MA, Wielopolski PA, Niessen WJ, Hofman $A$, et al. Prevalence and risk factors of cerebral microbleeds: the Rotterdam Scan Study. Neurology 2008;70:1208-1214.

117. Harris $T B$, Launer $\sqcup$, Eiriksdottir G, Kjartansson 0 , Jonsson PV, Sigurdsson G, et al. Age, Gene/Environment SusceptibilityReykjavik Study: multidisciplinary applied phenomics. Am J Epidemiol 2007;165:1076-1087.

118. Akoudad S, Portegies ML, Koudstaal PJ, Hofman A, van der Lugt $A$, Ikram MA, et al. Cerebral microbleeds are associated with an increased risk of stroke: the Rotterdam Study. Circulation 2015;132:509-516.

119. Song TJ, Kim J, Kim YD, Nam HS, Lee HS, Nam CM, et al. The distribution of cerebral microbleeds determines their association with arterial stiffness in non-cardioembolic acute stroke patients. Eur J Neurol 2014;21:463-469.

120. Vernooij MW, Haag MD, van der Lugt $A$, Hofman $A$, Krestin $\mathrm{GP}$, Stricker $\mathrm{BH}$, et al. Use of antithrombotic drugs and the presence of cerebral microbleeds: the Rotterdam Scan Study. Arch Neurol 2009;66:714-720.

121. Kakar P, Charidimou A, Werring DJ. Cerebral microbleeds: a new dilemma in stroke medicine. JRSM Cardiovasc Dis 2012; 1:2048004012474754.

122. Altmann-Schneider I, Trompet $S$, de Craen AJ, van Es AC, Jukema JW, Stott DJ, et al. Cerebral microbleeds are predictive of mortality in the elderly. Stroke 2011;42:638-644.

123. van Es $A C$, van der Grond J, de Craen AJ, Westendorp RG, Bollen EL, Blauw GJ, et al. Cerebral microbleeds and cognitive functioning in the PROSPER study. Neurology 2011;77: 1446-1452.

124. Choi P, Ren M, Phan TG, Callisaya M, Ly JV, Beare R, et al. Silent infarcts and cerebral microbleeds modify the associations of white matter lesions with gait and postural stability: population-based study. Stroke 2012;43:1505-1510.

125. Qiu C, Cotch MF, Sigurdsson S, Jonsson PV, Jonsdottir MK, Sveinbjrnsdottir $\mathrm{S}$, et al. Cerebral microbleeds, retinopathy, and dementia: the AGES-Reykjavik Study. Neurology 2010;75: 2221-2228.

126. Akoudad S, Wolters FJ, Viswanathan A, de Bruijn RF, van der Lugt $A$, Hofman $A$, et al. Association of cerebral microbleeds with cognitive decline and dementia. JAMA Neurol 2016;73: 934-943.

127. Romero JR, Beiser A, Himali JJ, Shoamanesh A, DeCarli C, Seshadri S. Cerebral microbleeds and risk of incident dementia: the Framingham Heart Study. Neurobiol Aging 2017;54:94-99.

128. Weller RO, Subash M, Preston SD, Mazanti I, Carare RO. Symposium: clearance of $A \beta$ from the brain in Alzheimer's disease: perivascular drainage of amyloid- $\beta$ peptides from the brain and its failure in cerebral amyloid angiopathy and Alzheimer's disease. Brain Pathol 2008;18:253-266.

129. Charidimou $A$, Meegahage $R$, Fox $Z$, Peeters $A$, Vandermeeren $Y$, Laloux $P$, et al. Enlarged perivascular spaces as a marker of underlying arteriopathy in intracerebral haemorrhage: a multicentre MRI cohort study. J Neurol Neurosurg Psychiatry 2013;84:624-629.

130. Martinez-Ramirez $S$, Pontes-Neto OM, Dumas AP, Auriel $E_{1}$ Halpin A, Quimby $M$, et al. Topography of dilated perivascular spaces in subjects from a memory clinic cohort. Neurology 2013;80:1551-1556.

131. Yakushiji $Y$, Charidimou $A$, Hara $M$, Noguchi $T$, Nishihara $M$, Eriguchi $M$, et al. Topography and associations of perivascular spaces in healthy adults: the Kashima scan study. Neurology 2014;83:2116-2123.

132. Zhu YC, Dufouil C, Mazoyer B, Soumaré A, Ricolfi F, Tzourio $C_{\text {, et }}$ al. Frequency and location of dilated Virchow-Robin spaces in elderly people: a population-based 3D MR imaging study. AJNR Am J Neuroradiol 2011;32:709-713.

133. Ramirez J, Berezuk C, McNeely AA, Scott CJ, Gao F, Black SE. Visible Virchow-Robin spaces on magnetic resonance imaging of Alzheimer's disease patients and normal elderly from the Sunnybrook Dementia Study. J Alzheimers Dis 2015;43: 415-424.

134. Zhu YC, Tzourio C, Soumaré A, Mazoyer B, Dufouil C, Chabriat $H$. Severity of dilated Virchow-Robin spaces is associated with age, blood pressure, and MRI markers of small vessel disease: a population-based study. Stroke 2010;41:2483-2490.

135. Bokura $H$, Kobayashi $S$, Yamaguchi S. Distinguishing silent lacunar infarction from enlarged Virchow-Robin spaces: a magnetic resonance imaging and pathological study. J Neurol 1998;245:116-122.

136. Ding J, Sigurősson S, Jónsson PV, Eiriksdottir G, Charidimou A, 
Lopez $\mathrm{OL}$, et al. Large perivascular spaces visible on magnetic resonance imaging, cerebral small vessel disease progression, and risk of dementia: the Age, Gene/Environment Susceptibility-Reykjavik Study. JAMA Neurol 2017;74:1105-1112.

137. Maclullich AM, Wardlaw JM, Ferguson KJ, Starr JM, SeckI JR, Deary IJ. Enlarged perivascular spaces are associated with cognitive function in healthy elderly men. J Neurol Neurosurg Psychiatry 2004;75:1519-1523.

138. Patankar TF, Mitra D, Varma A, Snowden J, Neary D, Jackson A. Dilatation of the Virchow-Robin space is a sensitive indicator of cerebral microvascular disease: study in elderly patients with dementia. AJNR Am J Neuroradiol 2005;26:1512-1520.

139. Arba F, Quinn TJ, Hankey GJ, Lees KR, Wardlaw JM, Ali M, et al. Enlarged perivascular spaces and cognitive impairment after stroke and transient ischemic attack. Int J Stroke 2018;13:47-56.

140. Zhu YC, Dufouil C, Soumaré A, Mazoyer B, Chabriat H, Tzourio $C$. High degree of dilated Virchow-Robin spaces on MRI is associated with increased risk of dementia. J Alzheimers Dis 2010;22:663-672.

141. Vernooij MW, Ikram MA, Hofman A, Krestin GP, Breteler MM, van der Lugt A. Superficial siderosis in the general population. Neurology 2009;73:202-205.

142. Charidimou A, Linn J, Vernooij MW, Opherk C, Akoudad S, Baron JC, et al. Cortical superficial siderosis: detection and clinical significance in cerebral amyloid angiopathy and related conditions. Brain 2015;138:2126-2139.

143. Pichler $M$, Vemuri $P$, Rabinstein AA, Aakre J, Flemming KD, Brown RD Jr, et al. Prevalence and natural history of superficial siderosis: a population-based study. Stroke 2017;48: 3210-3214.

144. Roberts RO, Geda YE, Knopman DS, Cha RH, Pankratz VS, Boeve BF, et al. The Mayo Clinic study of aging: design and sampling, participation, baseline measures and sample characteristics. Neuroepidemiology 2008;30:58-69.

145. Shoamanesh A, Martinez-Ramirez S, Oliveira-Filho J, Reijmer Y, Falcone GJ, Ayres A, et al. Interrelationship of superficial siderosis and microbleeds in cerebral amyloid angiopathy. Neurology 2014;83:1838-1843.

146. Charidimou A, Martinez-Ramirez S, Shoamanesh A, OliveiraFilho J, Frosch $M$, Vashkevich $A$, et al. Cerebral amyloid angiopathy with and without hemorrhage: evidence for different disease phenotypes. Neurology 2015;84:1206-1212.

147. Smith EE, Schneider JA, Wardlaw JM, Greenberg SM. Cerebral microinfarcts: the invisible lesions. Lancet Neurol 2012;11: 272-282.

148. Brundel M, de Bresser J, van Dillen JJ, Kappelle ப, Biessels GJ. Cerebral microinfarcts: a systematic review of neuropatho- logical studies. J Cereb Blood Flow Metab 2012;32:425-436.

149. van Veluw SJ, Hilal S, Kuijf HJ, Ikram MK, Xin X, Yeow TB, et al. Cortical microinfarcts on 3T MRI: clinical correlates in memory-clinic patients. Alzheimers Dement 2015;11:15001509.

150. Hilal S, Sikking E, Shaik MA, Chan QL, van Veluw SJ, Vrooman H, et al. Cortical cerebral microinfarcts on 3T MRI: a novel marker of cerebrovascular disease. Neurology 2016;87:1583-1590.

151. Jouvent $E_{\text {, Poupon }}$, Gray F, Paquet $C$, Mangin JF, Le Bihan D, et al. Intracortical infarcts in small vessel disease: a combined 7-T postmortem MRI and neuropathological case study in cerebral autosomal-dominant arteriopathy with subcortical infarcts and leukoencephalopathy. Stroke 2011;42:e27-e30.

152. van Veluw SJ, Zwanenburg JJ, Engelen-Lee J, Spliet WG, Hendrikse J, Luijten PR, et al. In vivo detection of cerebral cortical microinfarcts with high-resolution 7T MRI. J Cereb Blood Flow Metab 2013;33:322-329.

153. van Veluw SJ, Heringa SM, Kuijf HJ, Koek HL, Luijten PR, Biessels GJ, et al. Cerebral cortical microinfarcts at 7 Tesla $\mathrm{MRI}$ in patients with early Alzheimer's disease. J Alzheimers Dis 2014;39:163-167.

154. van Dalen JW, Scuric EE, van Veluw SJ, Caan MW, Nederveen AJ, Biessels GJ, et al. Cortical microinfarcts detected in vivo on 3 Tesla MRI: clinical and radiological correlates. Stroke 2015;46:255-257.

155. Wityk RJ. Cerebral cortical microinfarcts on 3-t magnetic resonance imaging: a new tool in the study of cerebrovascular ischemia. JAMA Neurol 2017;74:385-386.

156. Ii $Y$, Maeda $M$, Kida $H$, Matsuo $K$, Shindo $A$, Taniguchi $A$, et al. In vivo detection of cortical microinfarcts on ultrahighfield MRI. J Neuroimaging 2013;23:28-32.

157. van Rooden S, Goos JD, van Opstal AM, Versluis MJ, Webb $A G$, Blauw GJ, et al. Increased number of microinfarcts in Alzheimer disease at 7-T MR imaging. Radiology 2014;270: 205-211.

158. Fu R, Wang Y, Wang Y, Liu L, Zhao $X$, Wang DZ, et al. The development of cortical microinfarcts is associated with intracranial atherosclerosis: data from the Chinese intracranial atherosclerosis study. J Stroke Cerebrovasc Dis 2015;24: 2447-2454.

159. Longstreth WT Jr, Sonnen JA, Koepsell TD, Kukull WA, Larson $E B$, Montine TJ. Associations between microinfarcts and other macroscopic vascular findings on neuropathologic examination in 2 databases. Alzheimer Dis Assoc Disord 2009;23: 291-294.

160. Wang LY, Larson EB, Sonnen JA, Shofer JB, McCormick W, Bowen JD, et al. Blood pressure and brain injury in older adults: findings from a community-based autopsy study. $J$ 
Am Geriatr Soc 2009;57:1975-1981.

161. Troncoso JC, Zonderman AB, Resnick SM, Crain B, Pletnikova 0,0 'Brien RJ. Effect of infarcts on dementia in the Baltimore longitudinal study of aging. Ann Neurol 2008;64:168-176.

162. Hilal S, Chai YL, van Veluw S, Shaik MA, Ikram MK, Venketasubramanian $\mathrm{N}$, et al. Association between subclinical cardiac biomarkers and clinically manifest cardiac diseases with cortical cerebral microinfarcts. JAMA Neurol 2017;74:403-410.

163. Zheng L, Vinters HV, Mack WJ, Zarow C, Ellis WG, Chui HC. Cerebral atherosclerosis is associated with cystic infarcts and microinfarcts but not Alzheimer pathologic changes. Stroke 2013;44:2835-2841.

164. Rosman M, Zheng Y, Wong W, Lamoureux E, Saw SM, Tay WT, et al. Singapore Malay Eye Study: rationale and methodology of 6-year follow-up study (SiMES-2). Clin Exp Ophthalmol 2012;40:557-568.

165. Hilal S, Ikram MK, Saini M, Tan CS, Catindig JA, Dong YH, et al. Prevalence of cognitive impairment in Chinese: epidemiology of dementia in Singapore study. J Neurol Neurosurg Psychiatry 2013;84:686-692.

166. Brundel M, Reijmer YD, van Veluw SJ, Kuijf HJ, Luijten PR, Kappelle $\sqcup$, et al. Cerebral microvascular lesions on highresolution 7-Tesla MRI in patients with type 2 diabetes. Diabetes 2014;63:3523-3529.

167. Pruzin JJ, Schneider JA, Capuano AW, Leurgans SE, Barnes LL, Ahima RS, et al. Diabetes, hemoglobin A1C, and regional Alzheimer disease and infarct pathology. Alzheimer Dis Assoc Disord 2017;31:41-47.

168. Yassi N, Hilal S, Lim YY, Salinas S, Kuijf H, Xia Y, et al. Cortical cerebral microinfarcts on 3T MRI in Alzheimer's disease and mild cognitive impairment. Alzheimers Dement 2017;13(7 Suppl):P1378-P1379.

169. Arvanitakis $Z$, Leurgans SE, Barnes LL, Bennett DA, Schneider JA. Microinfarct pathology, dementia, and cognitive systems. Stroke 2011;42:722-727.

170. Bennett DA, Schneider JA, Arvanitakis Z, Wilson RS. Overview and findings from the religious orders study. Curr Alzheimer Res 2012;9:628-645.

171. Bennett DA, Schneider JA, Buchman AS, Barnes LL, Boyle PA, Wilson RS. Overview and findings from the rush Memory and Aging Project. Curr Alzheimer Res 2012;9:646-663.

172. Arvanitakis Z, Capuano AW, Leurgans SE, Buchman AS, Bennett DA, Schneider JA. The relationship of cerebral vessel pathology to brain microinfarcts. Brain Pathol 2017;27:77-85.

173. Smith EE, Saposnik G, Biessels GJ, Doubal FN, Fornage M, Gorelick PB, et al. Prevention of stroke in patients with silent cerebrovascular disease: a scientific statement for healthcare professionals from the American Heart Association/American
Stroke Association. Stroke 2017;48:e44-e71.

174. Staals J, Makin SD, Doubal FN, Dennis MS, Wardlaw JM. Stroke subtype, vascular risk factors, and total MRI brain small-vessel disease burden. Neurology 2014;83:1228-1234.

175. Cuadrado-Godia E, Dwivedi $P$, Sharma S, Ois Santiago A, Roquer Gonzalez J, Balcells $M$, et al. Cerebral small vessel disease: a review focusing on pathophysiology, biomarkers, and machine learning strategies. J Stroke 2018;20:302-320.

176. Lau KK, Li L, Schulz U, Simoni M, Chan KH, Ho SL, et al. Total small vessel disease score and risk of recurrent stroke: validation in 2 large cohorts. Neurology 2017;88:2260-2267.

177. Poggesi A, Pasi M, Pescini F, Pantoni L, Inzitari D. Circulating biologic markers of endothelial dysfunction in cerebral small vessel disease: a review. J Cereb Blood Flow Metab 2016;36: 72-94.

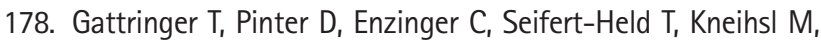
Fandler $\mathrm{S}$, et al. Serum neurofilament light is sensitive to active cerebral small vessel disease. Neurology 2017;89:2108-2114.

179. Duering M, Konieczny MJ, Tiedt S, Baykara E, Tuladhar AM, Leijsen EV, et al. Serum neurofilament light chain levels are related to small vessel disease burden. J Stroke 2018;20:228-238.

180. Markus HS, Hunt B, Palmer K, Enzinger C, Schmidt $H_{\text {, }}$ Schmidt R. Markers of endothelial and hemostatic activation and progression of cerebral white matter hyperintensities: longitudinal results of the Austrian Stroke Prevention Study. Stroke 2005;36:1410-1414.

181. van Dijk EJ, Prins ND, Vermeer SE, Vrooman HA, Hofman A, Koudstaal PJ, et al. C-reactive protein and cerebral small-vessel disease: the Rotterdam Scan Study. Circulation 2005;112: 900-905.

182. Satizabal CL, Zhu YC, Mazoyer B, Dufouil C, Tzourio C. Circulating IL-6 and CRP are associated with MRI findings in the elderly: the 3C-Dijon Study. Neurology 2012;78:720-727.

183. Rizzi L, Marques FC, Rosset I, Moriguchi EH, Picon PD, Chaves $\mathrm{ML}$, et al. C-reactive protein and cognition are unrelated to leukoaraiosis. ScientificWorldJournal 2014;2014:121679.

184. Schmidt R, Schmidt H, Pichler M, Enzinger C, Petrovic K, Niederkorn $\mathrm{K}$, et al. C-reactive protein, carotid atherosclerosis, and cerebral small-vessel disease: results of the Austrian Stroke Prevention Study. Stroke 2006;37:2910-2916.

185. Avci AY, Lakadamyali H, Arikan S, Benli US, Kilinc M. High sensitivity C-reactive protein and cerebral white matter hyperintensities on magnetic resonance imaging in migraine patients. J Headache Pain 2015;16:9.

186. Ashjazadeh N, Fathi M, Shariat A. Evaluation of homocysteine level as a risk factor among patients with ischemic stroke and its subtypes. Iran J Med Sci 2013;38:233-239.

187. Dufouil C, de Kersaint-Gilly $A_{1}$ Besançon V, Levy C, Auffray $E_{1}$ 


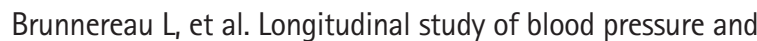
white matter hyperintensities: the EVA MRI cohort. Neurology 2001;56:921-926.

188. Fukuda $H$, Kitani M. Differences between treated and untreated hypertensive subjects in the extent of periventricular hyperintensities observed on brain MRI. Stroke 1995;26: 1593-1597.

189. de Leeuw FE, de Groot JC, Oudkerk M, Witteman JC, Hofman A, van Gijn J, et al. Hypertension and cerebral white matter lesions in a prospective cohort study. Brain 2002;125:765-772.

190. Firbank MJ, Wiseman RM, Burton EJ, Saxby BK, O'Brien JT, Ford GA. Brain atrophy and white matter hyperintensity change in older adults and relationship to blood pressure. Brain atrophy, WMH change and blood pressure. J Neurol 2007;254:713-721.

191. Dufouil C, Chalmers J, Coskun O, Besançon V, Bousser MG, Guillon $\mathrm{P}$, et al. Effects of blood pressure lowering on cerebral white matter hyperintensities in patients with stroke: the PROGRESS (Perindopril Protection Against Recurrent Stroke Study) Magnetic Resonance Imaging Substudy. Circulation 2005;112:1644-1650.

192. Godin O, Tzourio C, Maillard P, Mazoyer B, Dufouil C. Antihypertensive treatment and change in blood pressure are associated with the progression of white matter lesion volumes: the Three-City (3C)-Dijon Magnetic Resonance Imaging Study. Circulation 2011;123:266-273.

193. van Middelaar T, Argillander TE, Schreuder FHBM, Deinum J, Richard E, Klijn CJM. Effect of antihypertensive medication on cerebral small vessel disease: a systematic review and meta-analysis. Stroke 2018;49:1531-1533.

194. Weber R, Weimar C, Blatchford J, Hermansson K, Wanke I,

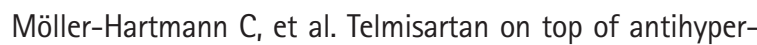
tensive treatment does not prevent progression of cerebral white matter lesions in the prevention regimen for effectively avoiding second strokes (PRoFESS) MRI substudy. Stroke 2012;43:2336-2342.

195. Vuorinen $M$, Solomon A, Rovio S, Nieminen L, Kåreholt I, Tuomilehto $\mathrm{J}$, et al. Changes in vascular risk factors from midlife to late life and white matter lesions: a 20-year follow-up study. Dement Geriatr Cogn Disord 2011;31:119-125.

196. Mok VC, Lam WW, Fan YH, Wong A, Ng PW, Tsoi TH, et al. Effects of statins on the progression of cerebral white matter lesion: post hoc analysis of the ROCAS (Regression of Cerebral Artery Stenosis) study. J Neurol 2009;256:750-757.
197. Xiong Y, Wong A, Cavalieri M, Schmidt R, Chu WW, Liu X, et al. Prestroke statins, progression of white matter hyperintensities, and cognitive decline in stroke patients with confluent white matter hyperintensities. Neurotherapeutics 2014;11: 606-611.

198. ten Dam VH, van den Heuvel DM, van Buchem MA, Westendorp RG, Bollen EL, Ford I, et al. Effect of pravastatin on cerebral infarcts and white matter lesions. Neurology 2005;64: 1807-1809.

199. Bernick C, Katz R, Smith NL, Rapp S, Bhadelia R, Carlson M, et al. Statins and cognitive function in the elderly: the Cardiovascular Health Study. Neurology 2005;65:1388-1394.

200. Jongen C, van der Grond J, Kappelle L, Biessels GJ, Viergever MA, Pluim JP, et al. Automated measurement of brain and white matter lesion volume in type 2 diabetes mellitus. Diabetologia 2007;50:1509-1516.

201. van Harten $B$, de Leeuw FE, Weinstein HC, Scheltens P, Biessels GJ. Brain imaging in patients with diabetes: a systematic review. Diabetes Care 2006;29:2539-2548.

202. Torres ER, Strack EF, Fernandez CE, Tumey TA, Hitchcock ME. Physical activity and white matter hyperintensities: a systematic review of quantitative studies. Prev Med Rep 2015;2:319325.

203. Rha JH, Park HK, Park JJ, Yoo NY. Is antiplatelet treatment effective on the progression of white matter hyperintensity?: 5 year follow up, propensity score adjusted, observational study. Neurology 2012;78(1 Suppl):P04.203.

204. Yoon CW, Choi Y, Jeon S, Lee DH, Yoon BN, Park HK, et al. Is antiplatelet treatment effective at attenuating the progression of white matter hyperintensities? PLoS One 2017;12: e0176300.

205. Qiu J, Ye H, Wang J, Yan J, Wang J, Wang Y. Antiplatelet therapy, cerebral microbleeds, and intracerebral hemorrhage: a meta-analysis. Stroke 2018;49:1751-1754.

206. Wobith M, Mayer C, Belke M, Haag A, Gerstner A, Teepker M, et al. Predictors of new cerebral microbleeds in patients with antiplatelet drug therapy. J Stroke Cerebrovasc Dis 2016; 25:1671-1677.

207. Charidimou A, Shoamanesh A, Al-Shahi Salman R, Cordonnier $C$, Perry LA, Sheth KN, et al. Cerebral amyloid angiopathy, cerebral microbleeds and implications for anticoagulation decisions: the need for a balanced approach. Int J Stroke 2018;13:117-120. 